\title{
Chemical composition and aerosol size distribution of the middle mountain range in the Nepal Himalayas during the 2009 pre-monsoon season
}

\author{
P. Shrestha, A. P. Barros, and A. Khlystov \\ Pratt School of Engineering, Duke University, Durham NC 27708, USA \\ Received: 18 May 2010 - Published in Atmos. Chem. Phys. Discuss.: 25 June 2010 \\ Revised: 9 November 2010 - Accepted: 27 November 2010 - Published: 8 December 2010
}

\begin{abstract}
Aerosol particle number size distribution and chemical composition were measured at two low altitude sites, one urban and one relatively pristine valley, in Central Nepal during the 2009 pre-monsoon season (May-June). This is the first time that aerosol size distribution and chemical composition were measured simultaneously at lower elevations in the middle Himalayan region in Nepal. The aerosol size distribution was measured using a Scanning Mobility Particle Sizer (SMPS, 14-340 nm), and the chemical composition of the filter samples collected during the field campaign was analyzed in the laboratory. Teflon membrane filters were used for ion chromatography (IC) and watersoluble organic carbon and nitrogen analysis. Quartz fiber filters were used for organic carbon and elemental carbon analysis. Multi-lognormal fits to the measured aerosol size distribution indicated a consistent larger mode around $100 \mathrm{~nm}$ which is usually the oldest, most processed background aerosol. The smaller mode was located around $20 \mathrm{~nm}$, which is indicative of fresh but not necessarily local aerosol. The diurnal cycle of the aerosol number concentration showed the presence of two peaks (early morning and evening), during the transitional periods of boundary layer growth and collapse. The increase in number concentration during the peak periods was observed for the entire size distribution. Although the possible contribution of local emissions in size ranges similar to the larger mode cannot be completely ruled out, another plausible explanation is the mixing of aged elevated aerosol in the residual layer during the morning period as suggested by previous studies. Similarly, the evening time concentration peaks when the boundary layer becomes shal-
\end{abstract}

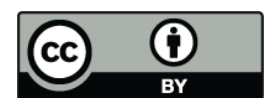

Correspondence to: A. P. Barros (barros@duke.edu) low concurrent with increase in local activity. A decrease in aerosol number concentration was observed during the nighttime with the development of cold (downslope) mountain winds that force the low level warmer air in the valley to rise. The mountain valley wind mechanisms induced by the topography along with the valley geometry appear to have a strong control in the diurnal cycle of the aerosol size distribution. During the sampling period, the chemical composition of $\mathrm{PM}_{2.5}$ was dominated by organic matter at both sites. Organic carbon (OC) comprised the major fraction (64-68\%) of the aerosol concentration followed by ionic species (24$26 \%$, mainly $\mathrm{SO}_{4}^{2-}$ and $\mathrm{NH}_{4}^{+}$). Elemental Carbon (EC) compromised $7-10 \%$ of the total composition and $27 \%$ of OC was found to be water soluble at both sites. The day-to-day variability observed in the time series of aerosol composition could be explained by the synoptic scale haze that extended to the sampling region from the Indian Gangetic Plain (IGP), and rainfall occurrence. In the presence of regional scale haze during dry periods, the mean volume aerosol concentration was found to increase and so did the aerosol mass concentrations.

\section{Introduction}

The southern slopes of the Himalaya in Nepal encompass the Terai (flat plains), Siwalik range (Churia hills), the Middle mountain (Mahabharat range) region and the High mountains. The Churia Hills are the outermost hills of the Himalayan system, separating the inner deep valleys in the middle mountain range from the Terai $(600 \mathrm{~m}$ in elevation) and the Indian Gangetic Plain (IGP). Major tributaries to the Ganges such as the Koshi, the Narayani, the Rapti, and the

Published by Copernicus Publications on behalf of the European Geosciences Union. 
Karnali along with other small rivers mostly originating from the Himalayas cut through the Churia hills before reaching the IGP. The valleys of these rivers create deep narrow pockets suitable for the accumulation of aerosols advected into the region from the low lying Indian Gangetic Plains, thus modulating their spatial distribution along the Middle mountain region. This potentially has a strong effect on the microphysics of orographic precipitation in this region by modulating the cloud condensation nuclei $(\mathrm{CCN})$ spectrum (the so called indirect effect). Since both riming and collision of water droplets following coalescence is prerequisite for efficient precipitation (White et al., 2003; Lascaux et al., 2006; Rotunno and Houze, 2007), inhibition of this cloud microphysical process due to an increase in $\mathrm{CCN}$ concentration influences the precipitation efficiency of the system (Barros and Lettenmaier, 1994; Rosenfeld and Lensky, 1998; Khain et al., 2000; Ramanathan et al., 2001; Andreae et al., 2004; Tao et al., 2007; Lau et al., 2008; and many others). In order to study the aerosol indirect effect, a direct measurement of the CCN spectrum is required or, alternatively, it can be estimated from observed aerosol size distribution and chemical composition. The latter provides a strong physical basis to study the aerosol indirect effect as it links the $\mathrm{CCN}$ spectrum to the observed aerosol size distribution and its physical properties (Razzaq et al., 1998; Cohard et al., 2000; Khvorostyanov and Curry, 2006).

Very few studies have been conducted to measure the aerosol size distribution in Nepal, and most of those have been limited to very high altitude regions: Ikegami et al. (1978) measured the size spectrum of background aerosol observed at Shorong Base Camp (Nepal, $4900 \mathrm{~m}$ ), and Venzac et al. (2008) report on the aerosol size distribution (diameter range 10-700 nm) in the Khumbu Valley (5079 m). Hindmann and Upadhyay (2002) measured condensation nuclei $(\mathrm{CN})$ at different elevations $(1300-5000 \mathrm{~m})$, and suggested that valley winds may be responsible for transporting pollution from the valley to the ridges. Recently, the role of ridge-valley circulation for Kathmandu Valley was explored in detail by Panday and Prinn (2009) and Panday et al. (2009) to explain the observed diurnal cycle of carbon monoxide (CO) in the valley. However, no field campaigns were previously undertaken to measure the aerosol size distribution in the mid and lower altitude ridge-valley regions, where orographic precipitation could be modulated by the aerosol haze extending from the IGP.

The chemical composition of aerosol in the Himalayas has been studied in detail by Shrestha et al. $(2000,2002)$, Carrico et al. (2003) and Stone et al. (2009). In particular, Shrestha et al. (2000) conducted a 15 month long study of inorganic aerosol species at Phortse (4100 ma.m.s.l.; $27.351^{\circ} \mathrm{N} 86.345^{\circ}$ E, September $1996-$ November 1997$)$ and Jiri (1900 m a.m.s.l.; $27.338^{\circ}$ N $86.314^{\circ}$ E, September $1996-$ October 1997) that revealed seasonal variations in the soluble inorganic component of aerosol which they attributed to changes in atmospheric circulation. Carrico et al. (2003) re- ported the monthly averages of ground -based measurements of chemical and optical properties of aerosols at two locations in Nepal: (Langtang $28.13^{\circ} \mathrm{N}, 85.60^{\circ} \mathrm{E}, 3920 \mathrm{~m}$ and Nagarkot, $27.72^{\circ} \mathrm{N}, 85.52^{\circ} \mathrm{E}, 2150 \mathrm{~m}$ ) from 1999 to 2000. Their study showed a prominent seasonal pattern associated with the Asian monsoon, featuring a peak aerosol concentration in February-May (pre-monsoon season). They also attributed the seasonal variation in aerosol chemical properties to synoptic scale weather patterns: dry air masses brought by strong westerlies during the pre-monsoon and the post monsoon seasons, and moist air masses transported by weak southerly flow during the monsoon, suggesting that well mixed air masses affect the ground based observations in both cases. The composition of aerosol reported by Carrico et al. (2003) was dominated by organic matter, $\mathrm{SO}_{4}^{2-}, \mathrm{NH}_{4}^{+}$ and $\mathrm{NO}_{3}^{-}$, and a substantial portion of the $\mathrm{PM}_{2.5}$ mass was water insoluble and non-carbonaceous $(25 \%-45 \%)$. Stone et al. (2009) reported similar monthly averages for organic matter, and the ratio of unidentified mass to the $\mathrm{PM}_{2.5}$ mass from 1 year sampling at Godavari, southern edge of Kathmandu Valley. The fraction of soluble ionic species along with their chemical composition provides supplementary information in determining the $\mathrm{CCN}$ characteristics, but little or no information is known about the aerosol size spectrum over these valleys from which preliminary estimates of CCN can be deduced. In addition, due to the dominance of organic species, the soluble organic fraction also has an important effect in correctly determining the CCN spectrum.

Here, we report on simultaneous ground measurements of aerosol size distribution along with the chemical composition of aerosols using Scanning Mobility Particle Sizer (SMPS) and three different filters during the Joint Aerosol Monsoon Experiment (JAMEX, May-June 2009) in Central Nepal. Two sites were selected for sampling: the first site is relatively urban and near a large local source (Kathmandu Valley), the second site is a remote small rural town at the bottom of the Marsyangdi river valley, enroute to a popular Annapurna trekking trail. Data from these two sites permit intercomparison of aerosol size distribution for very different local conditions to assess the relative contribution of the locally generated aerosols and the IGP haze extending into the region. In this manuscript, we present an analysis of the variability of the local aerosol size distributions and major aerosol chemical components, including watersoluble organic material. The observations are interpreted in the context of local meteorology and the large scale circulation during the sampling period. The estimation of hygroscopic growth factors and the linkages of aerosol properties with CCN activation parameters will be addressed in a forthcoming paper. The manuscript is organized as follows: Sect. 2 describes the selection of sites, field measurements and analysis description. Results are discussed in detail in Sect. 3. Finally, summary and conclusions are presented in Sect. 4. 


\section{Experimental method}

Earlier ground based measurements at different elevations on the southern slopes of the Himalayan range revealed the occurrence of episodes of regional scale pollutant transport from the low-lying Indian Gangetic Plain (IGP) and the development of south-westerlies during the pre-monsoon season. However, ground based measurements are always affected by local emissions (natural or anthropogenic) and long-range transport cannot be easily distinguished from local sources. Conceptually, the ideal sampling location should be remote, and the data should have a high signal to noise ratio, where the signal would be the long range transport, and the noise would be the local emission. However, such locations will also typically lack proper access roads, electricity and other necessary utilities to conduct field experiments. Furthermore, such sites also have their own natural variability: for example, Bonasoni et al. (2008) reported locally suspended dust particles at a high altitude sampling site in Khumbu $(5059 \mathrm{~m})$. In this study, the two locations are in populated areas.

Two sampling sites were chosen during this field experiment: one of the sites was downwind of the largest city in Nepal, Kathmandu Valley, and the other was at the small town of Besisahar, a relatively remote location in Central Nepal. Both locations are influenced by the large scale transport of pollutants from the IGP and by local sources, but the relative contributions of these should differ between the two sites. The timing of the field experiment was based upon the results from exploratory data analysis of remote sensing products retrieved from satellite-based sensors (e.g. Moderate Resolution Imaging Spectroradiometer (MODIS), Total Ozone Mapping Spectrometer (TOMS)), which showed that the aerosol build up over this region coincides with the pre-monsoon season (March-April-May), and is later washed away by the monsoon rain (June, July, August, September, hereafter JJAS) (Shrestha and Barros, 2010).

Ground based measurements of aerosols were conducted during the months of May-June, 2009. The urban site was located within the campus of Kathmandu University (KU), Dhulikhel $\left(27.601^{\circ} \mathrm{N}, 85.538^{\circ} \mathrm{E}, 1510 \mathrm{~m}\right.$, hereafter referred to as Site A, Fig. 1) and is $30 \mathrm{~km}$ southeast (downwind) of the Kathmandu Valley (approximately more than 2 million inhabitants). The instrumentation at Site A was placed on the roof top of a three storey building, surrounded by the premises of $\mathrm{KU}$, an agricultural field and playgrounds to the east, west and north and a few residential buildings in the south. Another major city, Banepa is located approximately $2.5 \mathrm{~km} \mathrm{NW}$ from the sampling site, and a densely populated housing area is located on the eastern hillside, $1.3 \mathrm{~km}$ from the sampling site. Because Dhulikhel is downwind of Kathmandu Valley, the influence of pollutants from the city is expected, and measurements are likely to represent a combination of well mixed aerosols from Kathmandu and the broader regional background. Regmi et al. (2003) indicated
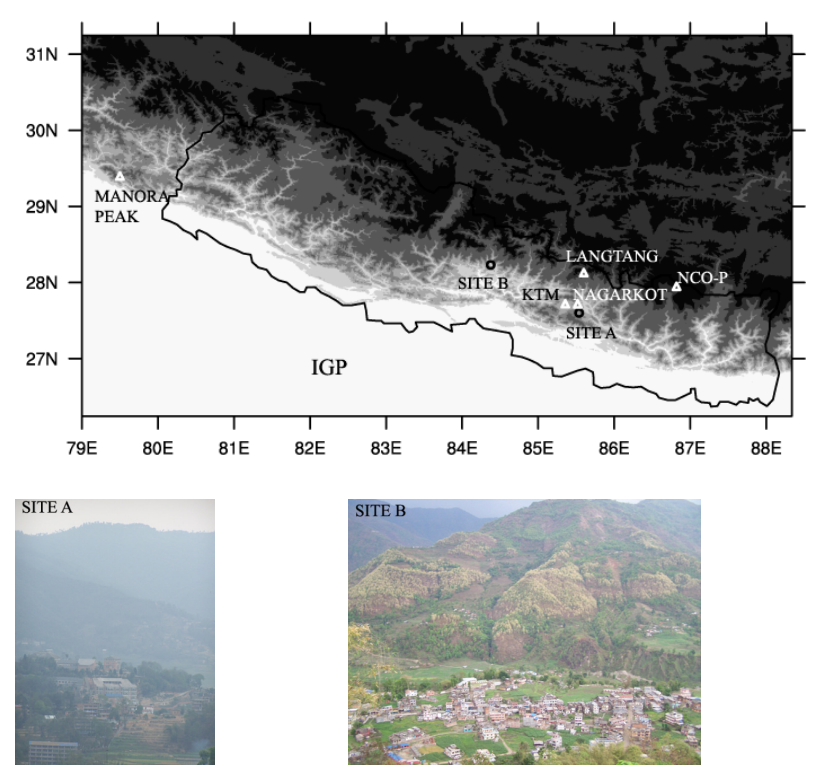

Fig. 1. Sampling locations: Site A (Dhulikhel), Site B (Besisahar) and nearby locations where previous studies on aerosol physical/chemical properties were carried out. Elevation contours are plotted at following levels: 500, 1000, 1500, 2000, 4000, $5000 \mathrm{~m}$. The elevation data was downloaded from the USGS gtopo30 data. The inset pictures of Site A and Site B were taken away from the sampling location and points towards south and west direction respectively. Scattered residential area along with some agriculture fields can be seen in Site B. The Site A shows only Kathmandu University which is actually surrounded by Dhulikhel city to the east and Banepa Valley in the west, with cascades of hills to the south.

that the major surface winds in the Kathmandu Valley are southwesterly and northwesterly, which merge into the westerly wind channeled to Banepa Valley. During the night time and early morning, the Kathmandu Valley is filled by a thick cold air pool at low elevations favored by the bowl shaped topography of the high mountains (Regmi et al., 2003). Thus, any transport of pollutants from the Kathmandu Valley to the sampling site at Kathmandu University is expected only during day time.

The second location, Besisahar $\left(28.232^{\circ} \mathrm{N}, 84.375^{\circ} \mathrm{E}\right.$, $786 \mathrm{~m}$, hereafter Site B) is at a low lying narrow crosssection in the Marsyangdi river valley (Fig. 1) with approximated area of $6.2 \mathrm{~km}^{2}, 42 \mathrm{~km}$ north of the main highway and a total population of 8616 (2001 census). The instrumentation at Site B was placed on the roof top of a twostorey building surrounded by residential areas and agriculture fields (growing maize) in the north, and in a close proximity to the hill on the south. The main local source of air pollutants is from household cooking (using primarily wood, kerosene and gasoline as fuel). Because of the NS orientation of the Marsyangdi river valley, Besisahar provides a relatively clean location to test the large scale transport of aerosols by southerly winds during the pre-monsoon season. 


\subsection{Aerosol size distribution measurements}

Scanning Mobility Particle Sizer (SMPS) was used to measure aerosol size distribution with sizes in the range $14 \mathrm{~nm}-$ $340 \mathrm{~nm}$. The SMPS was run continuously from 14 May to 25 May at Site A, and from 28 May to 6 June at Site B. The SMPS consisted of a Differential Mobility Analyzer (DMA, TSI model 3071) and a Condensation Particle Counter (CPC, TSI model 3010). The DMA was operated in sheath recirculation mode, the flow being provided by an AMETEK Minispiral blower. The flow rate was monitored using a mass flowmeter (TSI model 4140). The voltage was supplied to the DMAs by a high voltage power supply (Bertan model 605C). Flow rates check and leak tests were performed daily.

The aerosol size distribution data were fitted with multimode lognormal functions using one to four lognormal functions for each measured size distribution. The fit criterion was chosen to satisfy a $\chi^{2}$ goodness of fit test at $5 \%$ significance level with minimum number of modes.

\subsection{Filter sampling and analysis}

Filter sampling was conducted from 5 May to 25 May at Site A and 28 May to 6 June at Site B. Three parallel filter samples were collected over a nominal period of $12 \mathrm{~h}$ for Site A (07:00 a.m.-07:00 p.m.) and $21 \mathrm{~h}$ for Site B (10:00 a.m.-07:00 a.m. next morning): Teflon membrane for ion chromatography (IC), and water-soluble organic carbon (WSOC) analyses, Quartz fiber for organic carbon (OC) and elemental carbon (EC), and Polycarbonate membrane for Scanning Electron Microscopy (SEM) analysis. Filter sampling duration was regularly interrupted by power outages at both sites, reducing the actual sampling time, which was corrected based upon the data outage recorded by the SMPS and the relative humidity $(\mathrm{RH})$ sensors. The duration of each electricity outage was on average $1.22 \mathrm{~h}$ (approximately ranging from $0.5-2.5 \mathrm{~h}$ ) and $3.7 \mathrm{~h}$ (approximately ranging from $0.5 \mathrm{~h}$ to $6 \mathrm{~h}$ ) for Sites A and B respectively. The filter collection system was arranged as follows: the air was collected at $2 \mathrm{~m}$ above the surface through a Teflon-coated $\mathrm{PM}_{2.5}$ cyclone (URG Inc.). The flow after the cyclone was split into three lines: $15 \mathrm{~L} / \mathrm{min}$ for the Teflon filter, $11 \mathrm{~L} / \mathrm{min}$ for the quartz fiber filter, and $2 \mathrm{~L} / \mathrm{min}$ for the polycarbonate filter. Flow rates through the three filter lines were controlled by three critical orifices (BGI Inc.). Shorter sample duration (12 h) for Site A was used to avoid overloading the polycarbonate filters, which may render them useless for SEM (Scanning Electron Microscope) analysis (the polycarbonate filters have not yet been analyzed at this time). The samples were shipped between Nepal and the US in air-tight petridishes (along with dry ice) and kept frozen before analysis.

Teflon filters were extracted by placing them in $25 \mathrm{~mL}$ of double-dionized $(18 \mathrm{M} \Omega \mathrm{cm})$ water and sonicated for one hour. The extract was split into two equal parts. One part was used for determining the major inorganic aerosol species: $\mathrm{Na}^{+}, \mathrm{NH}_{4}^{+}, \mathrm{K}^{+}, \mathrm{Ca}^{2+}, \mathrm{Mg}^{2+}, \mathrm{Cl}^{-}, \mathrm{NO}_{3}^{-}, \mathrm{SO}_{4}^{2-}$ using cation and anion ion chromatographs (IC, both Metrohm 761, the anion unit was equipped with a suppressor). The other part of the extract was used for WSOC (Water Soluble Organic Carbon) and WSN (Water Soluble Nitrogen) analysis using the high sensitivity TOC/TN analyzer (Shimadzu TOC-Vcsh). Since the TOC/TN instrument can not distinguish between water-soluble and water-insoluble components in the solution, the sample was filtered through a $0.2 \mu \mathrm{m}$ pore Teflon membrane filter to remove water-insoluble particles. Water Soluble Organic Nitrogen (WSON) was determined by subtracting the total nitrogen measured with the ICs from WSN measured with the TOC/TN. The details of the organic nitrogen determination using measurements of the total and inorganic nitrogen can be found in Lin et al. (2010).

Quartz-fiber filters were pre-baked in an oven at $500^{\circ} \mathrm{C}$ for $12 \mathrm{~h}$ to remove carbonaceous contamination prior to shipment to Nepal. The Quartz fiber filters were analyzed for organic carbon and elemental carbon content using a thermaloptical-transmission technique (Turpin et al., 1990) and the Sunset Laboratories Thermal Optical Transmittance (TOT) OC/EC (Organic Carbon/Elemental Carbon) analyzer was used. Blank filter samples were also taken at both sampling sites and used for correcting all the results obtained during the study.

\subsection{Local meteorology}

The local meteorological variables were measured simultaneously using a Väisälä weather station (WXT500) at both sites. Pressure, temperature, wind speed, wind direction and precipitation were measured continuously during the sampling period at intervals of $10 \mathrm{~s}$ and $5 \mathrm{~min}$ for Sites A and $\mathrm{B}$, respectively.

The 2009 monsoon advanced into Eastern Nepal on 23 June, thus delayed by roughly two weeks according to monsoon climatology. A large fraction of the country was much drier and warmer than normal before the onset. The precipitation in first week of June was primarily due to the western disturbances which generally become weaker and do not reach Nepal from the second week of June onward (Preliminary Weather Summary of Nepal, June 2009: DHM, http://www.dhm.gov.np/).

\section{Results}

\subsection{Local meteorology}

The pattern of wind speed and direction observed at Site A indicates southerly inflow (probably associated with downslope mountain wind from the southern hills) during the night till early morning. After 09:00 a.m., the wind direction rotates to become easterly (Fig. 2a). As solar heating increases, 
a)
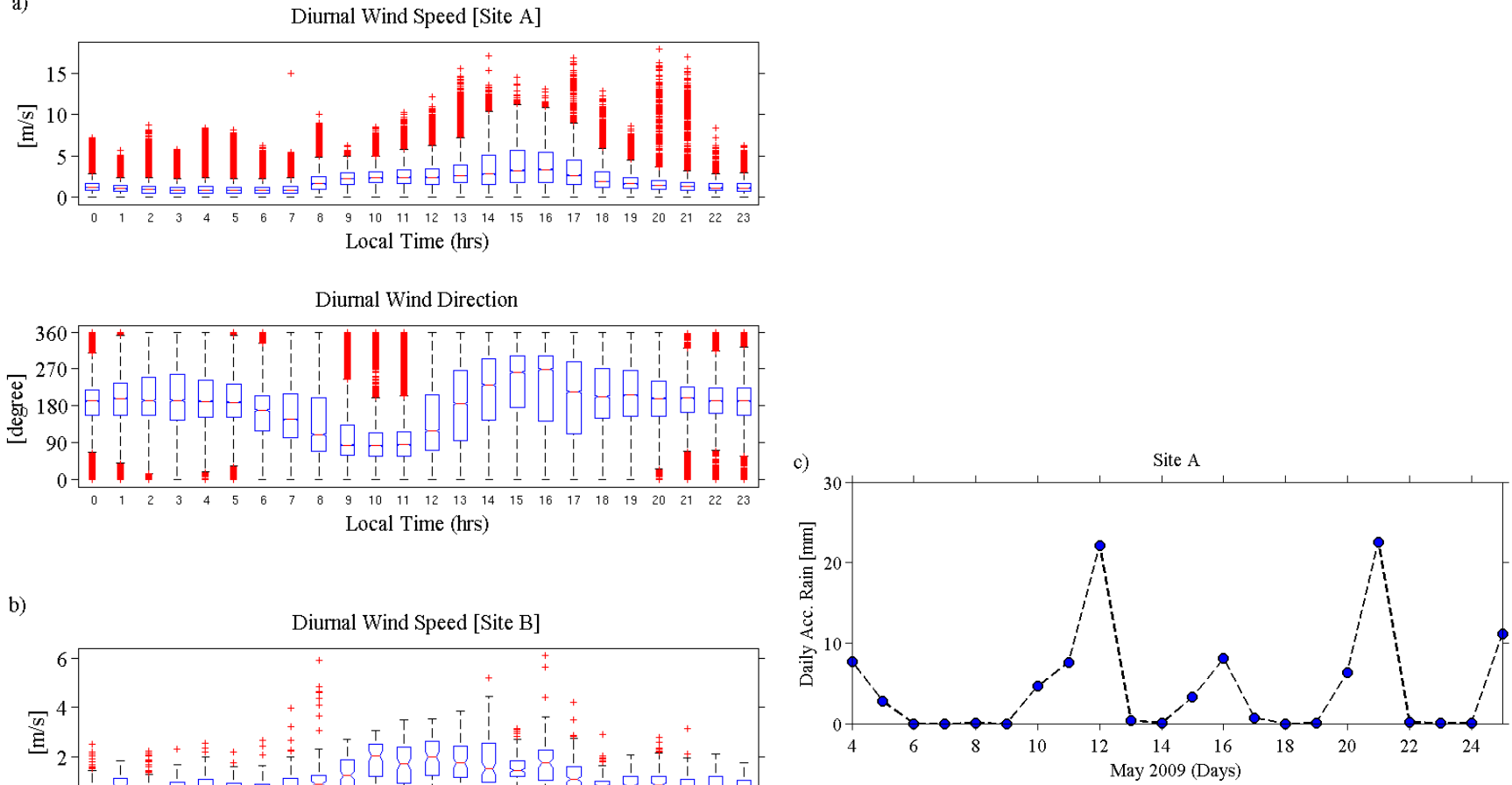

b)

Diurnal Wind Speed [Site B]
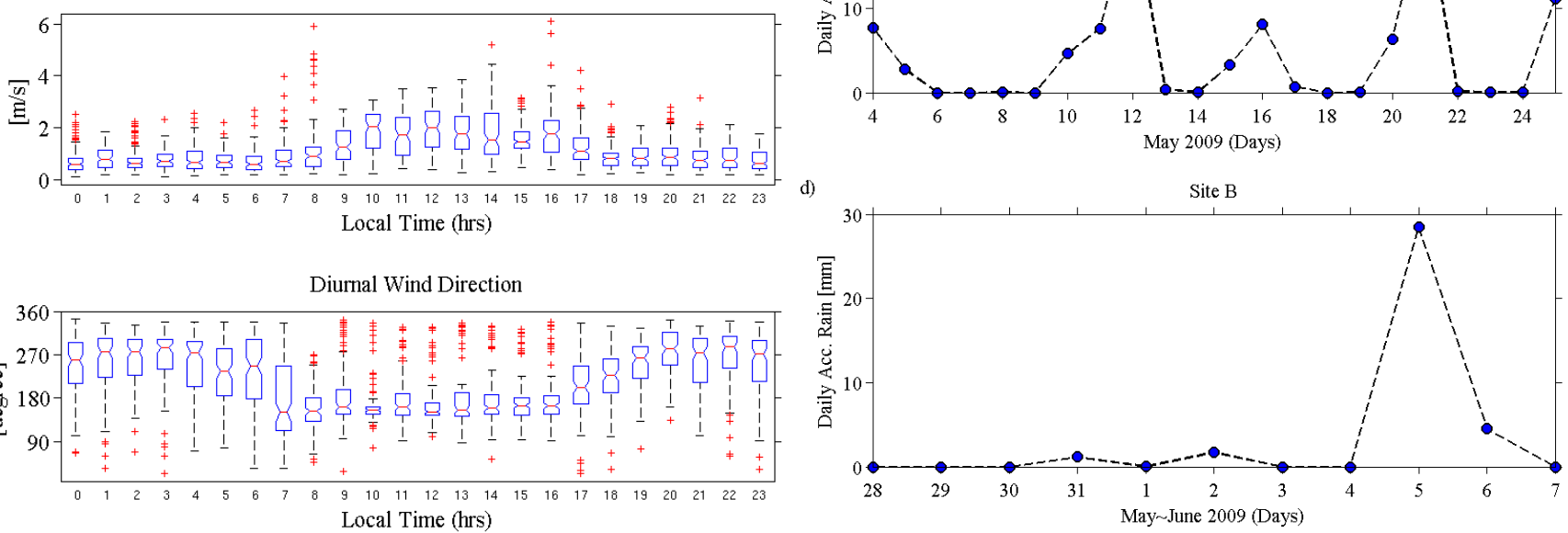

Fig. 2. Local Meteorological Variables measured during sampling: (a) and (b) diurnal wind speed and wind direction at Site A and Site B, respectively. The red-dots are the outliers which have a value more than 1.5 times the interquartile range away from the top and bottom of the box, (c) and (d) daily accumulated precipitation at Site A and Site B, respectively.

the wind direction rotates clockwise until it becomes westerly in the afternoon consistent with local ridge-valley circulations. The wind speed also reaches its diurnal maximum at this time. At Site B, the flow is westerly ranging from southwesterly to north-westerly at night time. During daytime, south-easterly flow develops from 09:00 a.m. to 04:00 p.m. with peak wind speeds around noon (Fig. 2b). These wind patterns suggest that the day time aerosol distribution is primarily affected by valley winds transporting air masses from the plains to the valleys, whereas at night, the cold mountain winds flow downward from the hill tops on the western flank of the sampling location.

There were periodic rainfall events observed at Site A associated with local thunderstorms and western disturbances that bring rainfall to Nepal during the pre-monsoon season (Barros et al., 2004). Figure 2c and d show the daily accumulated rainfall at Sites $\mathrm{A}$ and $\mathrm{B}$, respectively. The heavy precipitation event during sampling at Site B in the morning of June 5 was caused by a westerly disturbance (see Sect. 3.4 for discussion).

\subsection{Aerosol size distribution}

\subsubsection{General characteristics}

The aerosol size distribution at both locations exhibits significant variability on diurnal time scales. Figures 3 and 4 show the time series of aerosol size distribution, total number concentration, total volume concentration and geometric mean diameter for the entire sampling periods at Sites A and $\mathrm{B}$, respectively. The dates on the abscissa are marked at mid-night local time (LT). Two distinct peaks (morning and evening hours) in the number and volume concentration are present everyday for both sites. The aerosol concentrations 

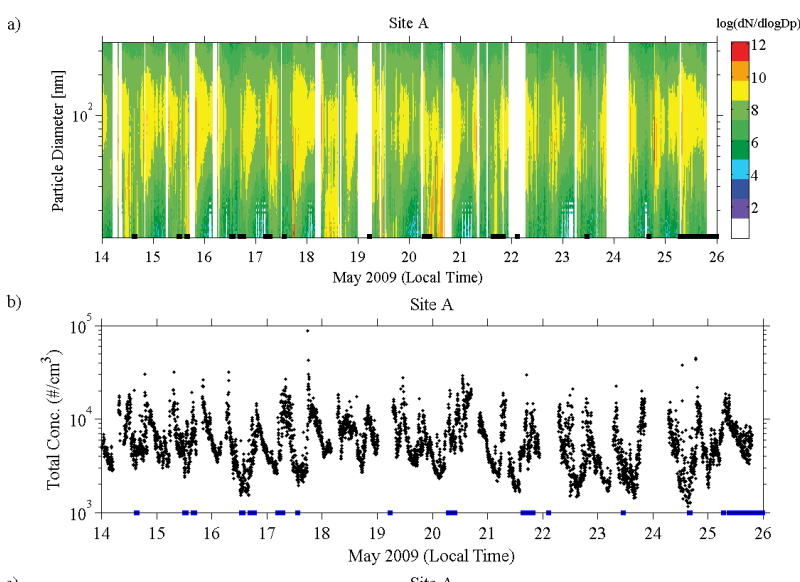

c)
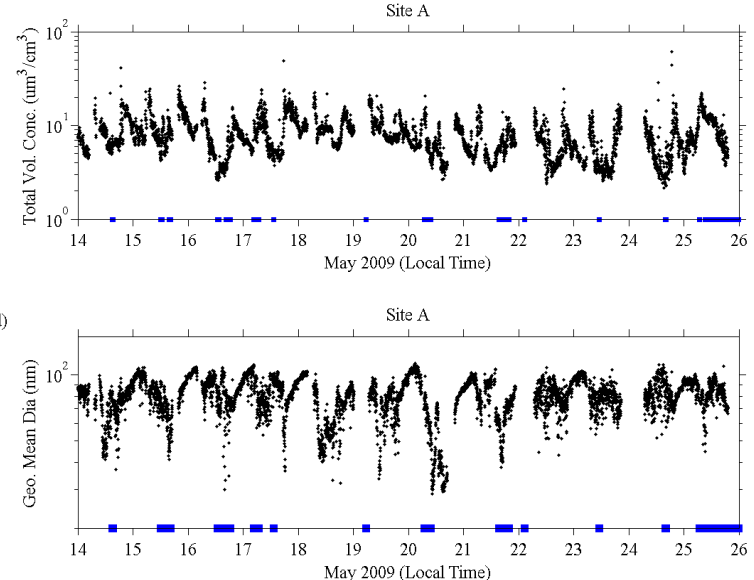

Fig. 3. Diurnal evolution of dry aerosol size distribution for Site A (Dhulikhel). (a) 2-D dry size distribution; (b) total number concentration $\left[\mathrm{cm}^{-3}\right]$; (c) total volume concentration $\left[\mathrm{nm}^{3} \mathrm{~cm}^{-3}\right]$ (d) Geometric Mean diameter [nm]. The discontinuities in the data are associated with electricity outages. The square dots (black/blue) on the bottom axis indicate precipitation events.

reach a daytime/nighttime minimum value in the afternoon and after midnight respectively, and the geometric mean of the size distribution also reaches its daytime/nighttime maximum during these periods. A sharp decrease in aerosol number concentration is observed during the precipitation events (marked by square black dots on the abscissa). Gaps in the data continuity are due to electricity outages, when no measurements could be made. The bulk statistics of the number and volume concentrations are presented for particle diameters $(D p<30 \mathrm{~nm}$ and $D p \geq 30 \mathrm{~nm})$ based upon the location of observed larger and smaller mode, which are discussed in further detail in Sect. 3.2.2. The average total number concentration ( \pm one standard deviation) of particles with diameter $(D p)$ between $30-340 \mathrm{~nm}$ was $5334 \pm 3355 \mathrm{~cm}^{-3}$ for the entire sampling period at Site A. Note that the standard deviation is of the same order of magnitude as the mean value, the coefficient of variation $[\mathrm{CV}=$ standard deviation/mean] is very high, and therefore the information con-
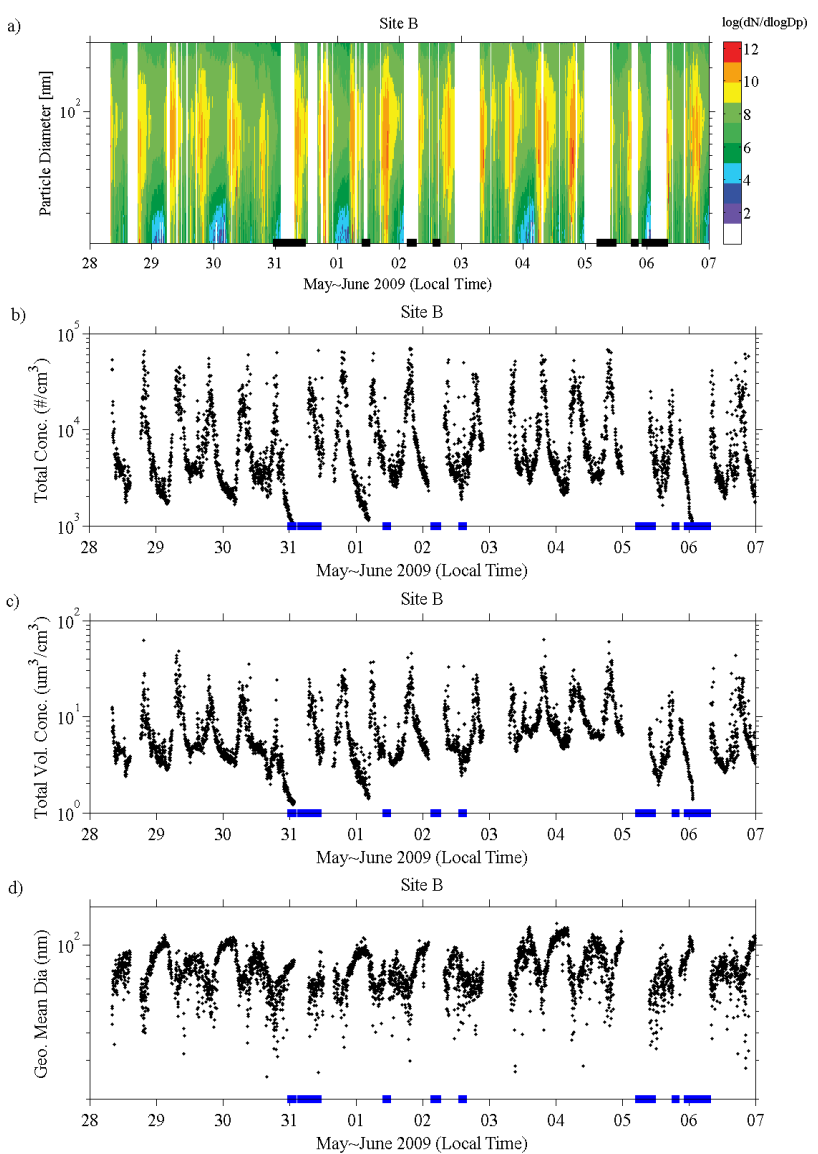

Fig. 4. Diurnal evolution of dry aerosol size distribution for Site B (Besisahar) (a) 2-D dry size distribution, (b) total number concentration $\left[\mathrm{cm}^{-3}\right]$; (c)total volume concentration $\left[\mathrm{nm}^{3} \mathrm{~cm}^{-3}\right]$; (d) Geometric Mean diameter [nm]. The discontinuities in the data are associated with electricity outages. The square dots (black/blue) on the bottom axis indicate precipitation events.

tent of bulk statistics is limited at best. Nevertheless, it is a standard reported in the literature, and thus it is reported here also. The corresponding average total volume concentration was $8 \pm 4 \mu \mathrm{m}^{3} \mathrm{~cm}^{-3}$ (calculated assuming spherical particles). For $D p<30 \mathrm{~nm}$, the average total number concentration at Site A was $850 \pm 1407 \mathrm{~cm}^{-3}(\mathrm{CV}>1)$ suggesting a very high day to day variability in Aitken mode particles. At Site B, the average total particle number and volume concentrations for $30-340 \mathrm{~nm}$ were $7566 \pm 8013 \mathrm{~cm}^{-3}$ and $7 \pm 6 \mu \mathrm{m}^{3} \mathrm{~cm}^{-3}$, respectively. The high variability in the reported mean concentrations for the entire sampling period at both the sites is caused by the two diurnal peaks in the morning and evening hours, so caution should be exercised in the use of grand means; instead, a better representative of aerosol concentration at both sites is given by the diurnal cycle discussed below. 
At both locations, the observed aerosol peaks take place when the wind speed is calm during the boundary layer (BL) transition growth in the morning and during the collapse of boundary layer in the evening preceding the nocturnal stable layer. For Site B, during the BL transition period, the wind veers from west to south in the morning (changing from downvalley to upvalley wind), and from south to west in evening (changing from upvalley to downvalley wind) (Fig. 2b). At Site A, the wind direction changes from south to east during the morning peak period with approximately southerly winds during the evening peak. The change in wind direction takes place in the afternoon, from easterly to more westerly (transporting aerosol from nearby cities, Banepa and the Kathmandu Valley, further away), and then back to southerly (Fig. 2a). The number concentration decreases as the wind speed starts to pick up during the daytime.

During the non-peak emission periods, the average total number concentration for $D p \geq 30 \mathrm{~nm}$ was $4054 \pm 2602 \mathrm{~cm}^{-3}$ and $3778 \pm 1043 \mathrm{~cm}^{-3}$ during the day (10:00 to $17: 00 \mathrm{LT})$ and at night $(23: 00$ to $04: 00 \mathrm{LT})$, respectively. Although the night time mean concentration of $D p<30 \mathrm{~nm}$ was low $\left(163 \mathrm{~cm}^{-3}\right)$, the day time mean concentration was still high and exhibited a strong variability $\left(1261 \pm 1971 \mathrm{~cm}^{-3}\right)$ suggesting a higher influence of Aitken mode particles throughout the day at Site A. The strong presence of Aitken mode particles during day time resulted in a lower geometric mean diameter of $74 \mathrm{~nm}$ which steadily increased to $96 \mathrm{~nm}$ at night (Fig. 3d). The corresponding total volume concentrations were $6 \pm 3 \mu \mathrm{m}^{3} \mathrm{~cm}^{-3}$ and $7 \pm 2 \mu \mathrm{m}^{3} \mathrm{~cm}^{-3}$ respectively. For Site B, the average number concentration for $D p \geq 30 \mathrm{~nm}$ was $3931 \pm 2856 \mathrm{~cm}^{-3}$ and $2252 \pm 803 \mathrm{~cm}^{-3}$ respectively for day time (10:00 to $17: 00$ h LT) and night time (23:00 to 04:00 h LT). The corresponding volume concentrations were $5 \pm 3 \mu \mathrm{m}^{3} \mathrm{~cm}^{-3}$ and $4 \pm 2 \mu \mathrm{m}^{3} \mathrm{~cm}^{-3}$, respectively. The geometric mean diameter increases from $78 \mathrm{~nm}$ (daytime) to $99 \mathrm{~nm}$ (night time) suggesting a decrease in Aitken mode particles (Fig. 4d). The nighttime mean total aerosol number concentration for $D p<30 \mathrm{~nm}$ was $59 \pm 76 \mathrm{~cm}^{-3}$ and $545 \pm 913 \mathrm{~cm}^{-3}$ respectively. Earlier, Komppula et al. (2009) reported mean aerosol concentrations of $4290 \mathrm{~cm}^{-3}$ during the month of MarchMay at a remote location with minimal local emission (Mukteshwar, India, adjacent to Manora Peak, see Fig. 1), which is lower than the observed mean for the whole sampling period at both sites in this study. This is primarily due to observed diurnal cycle of aerosols, with peaks in the morning and evening, documented in this current study. In fact, the daytime/nighttime averages are comparable and even lower than the seasonal mean total concentrations at Mukteshwar, India. Venzac et al. (2008) reported an average concentration of 560 $\pm 160 \mathrm{~cm}^{-3}$ from 03:00 to 08:00 LT throughout the measuring period in pre-monsoon season at the Himalayan Nepal Climate Observatory at Pyramid (NCO-P, see Fig. 1) site in the Khumbu Valley $(5079 \mathrm{~m})$, but the mean seasonal values peaked at $2000 \mathrm{~cm}^{-3}$ during day time. Recently, Sel- legri et al. (2010) report an integrated (nucleation, Aitken and accumulation mode) aerosol concentration of $1480 \mathrm{~cm}^{-3}$ (10:00 to 18:00 LT) and $675 \mathrm{~cm}^{-3}$ (03:00 to 08:00 LT) during the pre-monsoon season at NCO-P (May 2006 to May 2008). The corresponding volumetric concentration over the accumulation mode was $2.51 \mu^{3} \mathrm{~cm}^{-3}$ (10:00 to 19:00 LT) and $1.47 \mu \mathrm{m}^{3} \mathrm{~cm}^{-3}$ (03:00 to 08:00 LT). Both number and volume concentration indicated lower concentration during the night time. In this study, we also found lower concentration of aerosols at night time at both study sites (23:00 to 04:00 LT). However, the nighttime mean concentrations at Site A and B are respectively on the order of 6 and 3 times the measured mean nighttime concentration at NCO-P, which is representative more of a tropospheric background.

Figure $5 \mathrm{a}$ and $\mathrm{b}$ show the mean aerosol size distributions for the entire sampling period, including day and night time separately. Interestingly, Site B (rural) has a higher grand mean aerosol number concentration compared to Site A (urban), but the night time aerosol at Site B has a relatively lower concentration compared to Site A. The number concentration of the day time mean distribution at Site B for particles below $100 \mathrm{~nm}$ is much smaller than that at Site A, which exhibits high mean values below the accumulation mode. The higher aerosol number concentrations measured during the peak periods at Site B compared to Site A could be due to lower BL mixing associated with the narrow width and small cross-sectional area in the N-S oriented Marsyangdi river valley (Fig. 5d) during the transition periods of boundary layer growth in the early morning and boundary layer collapse in the evening as compared to the much wider bowl shaped landform of Dhulikhel, Site A (Fig. 5c). It is also possible that there may be some localized influence at Site B during traditional cooking hours due to the relatively higher density of the residential housing near the sampling station, which coincide with the timing of peak concentrations. Nevertheless, because of the narrow width and orientation of the Marsyangdi valley at Besisahar (Site B), the diurnal cycle of mountain-valley circulations is very consistent at this location independently of large-scale conditions (Barros and Lang, 2002), suggesting that Site B is suitable for monitoring the influence of large-scale aerosol transport from the IGP to the inner regions of the Himalayas.

The measured aerosol size distribution was fitted with multi-lognormal distributions, and a Pearson Chi Square test with $\alpha=0.05$ was used to select the distribution with $\chi^{2}$ value less than the $\chi_{\mathrm{cr}}$ and the minimum number of modes. Figure $6 \mathrm{a}$ and $\mathrm{b}$ show the frequency of occurrence of distributions with different number of lognormal modes during the observation period at Sites A and B, respectively. Bimodal distributions were most frequent, comprising $53 \%$ (Site A) and $45 \%$ (Site B) of observations. Unimodal distributions occurred $26 \%$ of the time at Site A and $34 \%$ of the time at Site B. The frequency of the trimodal distributions was higher at Site A (13\%) compared to Site B (8\%). However, the frequency of distributions with number of modes greater 

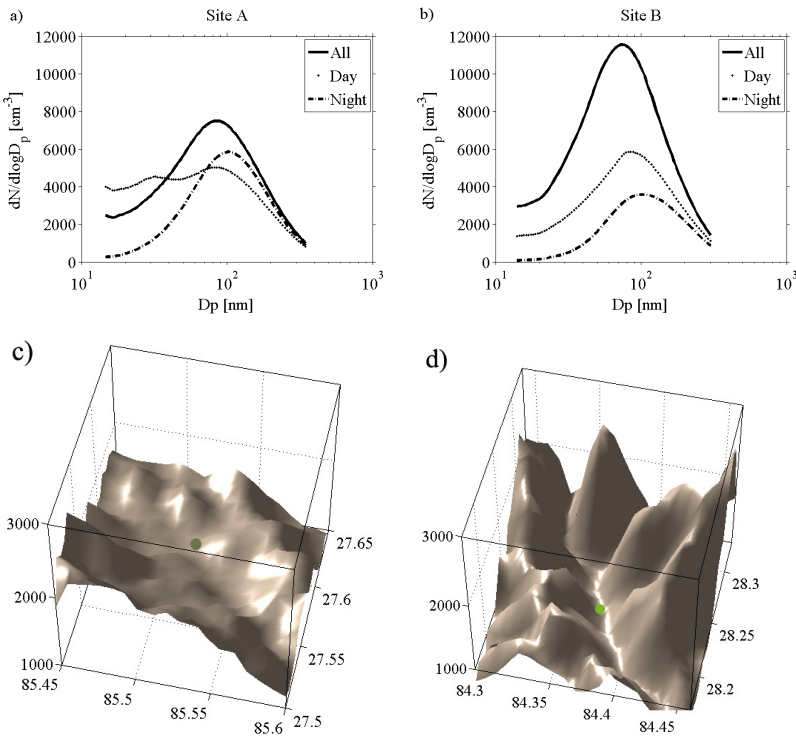

Fig. 5. Mean aerosol size distribution for the entire sampling period (a) Site A and (b) Site B. All represents the whole samples. Day represents the sampling done from 10:00-17:00 $\mathrm{h}$ LT and Night represents sampling period from 23:00-04:00 $\mathrm{h} \mathrm{LT}$. The windows used for day and night period filters out the sampling of locally emissions, (c-d) Topographic relief of sampling stations at Site A and Site B respectively, showing the narrow N-S oriented river valley for Site B compared to the open terrain of Site A, surrounded by series of small hills.

than three is higher at Site B (12\%) compared to Site A (6\%). That is, there is less modal variability at the urban Site A, than at the remote Site B. Overall, the fitted distributions exhibit a consistent dominant larger mode around $100 \mathrm{~nm}$ at both sites, which is indicative of the most processed background aerosol (Fig. 6c and d) upon which the smaller modes are superimposed whenever present. The dominant smaller mode is located around $20 \mathrm{~nm}$, and could be due to fresh particles from local sources or formed in nearby areas. The two dominant modes identified in this study are close to those identified by Venzac et al. (2008) and Komppula et al. (2009).

\subsubsection{Diurnal cycle}

The significant variability in aerosol size distribution observed on diurnal time scales along with consistent diurnal wind shifts motivated a detailed analysis of the data at subdaily time scales. Figure $7 \mathrm{a}$ and $\mathrm{b}$ show the composite diurnal cycle of the fitted aerosol size distributions for Site A and Site B respectively. Again, a consistent diurnal pattern of modal distributions is observed at Site B compared to Site A. The higher frequency of unimodal distributions at Site B compared to Site A can be attributed to the near absence of the bimodal distribution after midnight to early morning. Indeed, the diurnal cycle of unimodal distributions shows that they are dominant only at nighttime (23:00 to
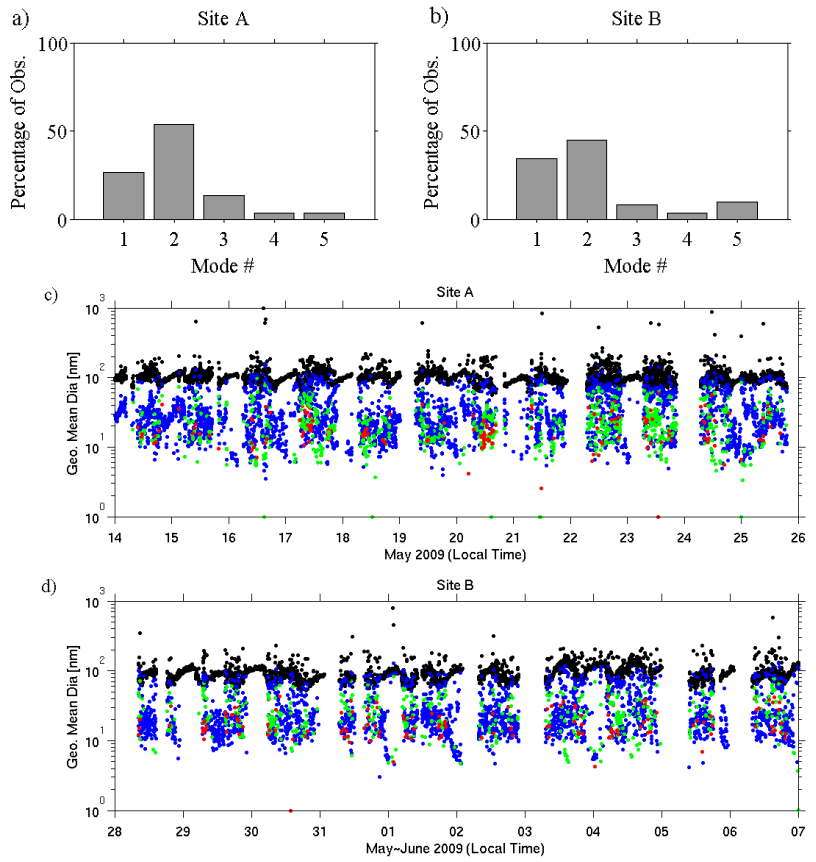

Fig. 6. (a-b) Modal distribution for dry aerosol size distribution. Multi-lognormal distribution was used to fit the observed spectra and a $\chi^{2}$ test was used to choose the distribution with lowest number of modes with $\alpha=0.05$. (c-d) Time evolution of fitted lognormal modes (geometric mean diameter of each mode).

04:00 LT) at both sites (Fig. 7a-b). Bimodal distributions are the dominant mode during daytime (10:00 to 17:00 LT at Site B and 07:00 to 20:00 LT at Site A). The diurnal cycle of multimodal distributions (number of modes $\geq 3$ ) indicates two distinct aerosol peaks, one in the morning $(05: 00$ to 10:00 LT) and the other in evening hours (17:00 to 20:00 LT) for Site B. These time periods coincide with the transition period of boundary layer growth and collapse (inferred from the vertical profile of virtual potential temperature estimated from the radiosonde sounding obtained over Besisahar (Site B) (Barros and Lang, 2003). Likewise, the composite diurnal cycle of the total number concentration over the sampling periods for Site A and Site B clearly displays these distinct peaks (Fig. 7c-d).

Both sampling sites exhibit a strong increase in number concentration in the morning (05:00 to 10:00 LT) and in the evening (17:00 to 22:00 LT). Similar increase in particle number concentration was observed by Rissler et al. (2006) for particle diameters less than $25 \mathrm{~nm}$ at a pasture site in southwestern Amazon region (Rondonia). In their study, the peak concentrations were observed from 04:00 a.m. to 08:00 a.m. in the morning and 05:00 p.m. to $11: 00 \mathrm{p} . \mathrm{m}$. in the evening. However, in Rondonia, the number concentration of particles with diameters $D p>30 \mathrm{~nm}$ decreased during the daytime reaching a minimum value and then increased till midnight and became stable till early morning. 

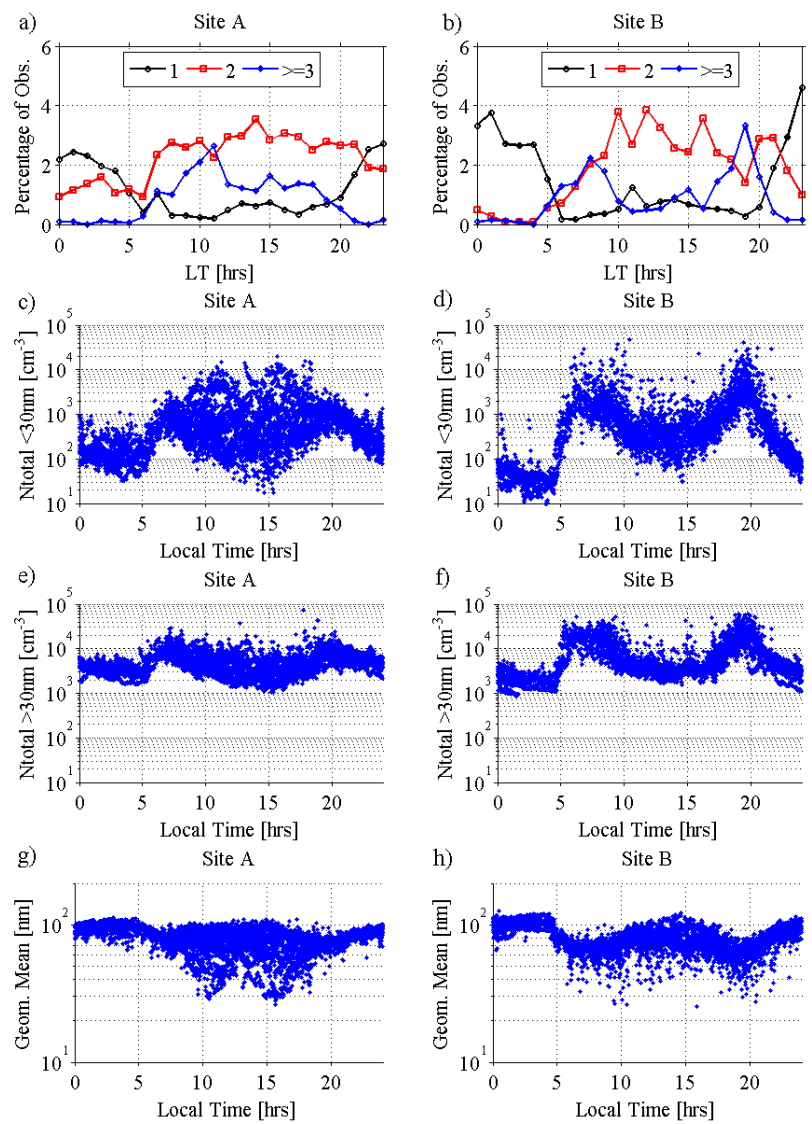

Fig. 7. (a-b) Diurnal evolution of fitted multi-lognormal distributions over the entire sampling period. Composite diurnal Cycle of the measured total number concentrations for the entire sampling period (c-d) $D p<30 \mathrm{~nm}$ and (e-f) $D p>30 \mathrm{~nm}$. (g-h) Composite diurnal Cycle of the geometric mean diameter of measured aerosol size distribution.

In this study, an increase in number concentrations was observed for particles with diameters $D p<30 \mathrm{~nm}$ as well as for $D p>30 \mathrm{~nm}$. Figure $7 \mathrm{c}-\mathrm{f}$ show that the contribution to the total number concentration during the peak periods is higher for $D p>30 \mathrm{~nm}$ than $D p<30 \mathrm{~nm}$. The observed peak in $D p>30 \mathrm{~nm}$ in the early morning could be related to mixing of elevated and aged background aerosol which remain aloft in the residual layer during the morning (Rissler et al., 2006; Panday and Prinn, 2009; Panday et al., 2009) which would increase the number concentration of larger mode. As the boundary layer develops during the day time, the total concentration for $D p>30 \mathrm{~nm}$ drops and tends to approach a minimum around 14:00-15:00 LT. The second peak in the evening for $D p>30 \mathrm{~nm}$ is associated with the decrease in the height of the boundary layer as the nocturnal stable layer forms, thus naturally favoring the increase in the concentration of the larger modes. Furthermore, the possibility of local emissions in the particle size range of the larger accumulation mode, especially during the peak periods cannot be neglected also. As the nocturnal stable layer forms at night, one would expect the concentrations to increase in the night as well, but katabatic winds developing at night lift the warm air mass in the valley, resulting in the decrease of the aerosol number concentration near the surface. Hence, mountain valley circulations play an important indirect role in modulating the diurnal cycle of low-level aerosol concentrations in the central Himalaya, which is mainly composed of series of river valleys of different shapes, sizes and orientation. The succession of these rivers valleys and ridges was also found to be linked to the spatial organization of the cloudiness in the Middle Himalayas (Barros et al., 2004). Previously, Panday and Prinn (2009) explained the observed semi-diurnal peak of carbon monoxide (CO) at Kathmandu valley (a bowl shaped valley, see Fig. 1) in terms of diurnal variations in emissions and ventilation. They suggested that strong ventilation from westerly winds lowered $\mathrm{CO}$ level during the afternoon in the Kathmandu Valley, while CO concentration reduction at night time was explained by the lifting of polluted air due to formation of a cold pool in the valley. Further, Panday et al. (2009) used MM5 to simulate the Kathmandu Valley's meteorology and study the dynamics of the basins' nocturnal cold air pool, using a nested grid with the highest resolution of $1 \mathrm{~km}$. They suggested that subsidence warming was present in both summer and winter simulation over Kathmandu Valley for the dissipation of the nocturnal cold air pool. They used back-of-the envelope calculations to confirm the subsidence in their simulation, which also supports the role of mixing of elevated aerosols in residual layers during boundary layer growth in the morning.

On the other hand, the amplitude of the diurnal peaks at Site B are significantly larger than at Site A (Fig. 7c-f), even for aerosol particles with $D p<30 \mathrm{~nm}$ (Site B: the concentration increases from $50 \mathrm{~cm}^{-3}$ to $3000 \mathrm{~cm}^{-3}$; Site A: the concentration increases from $100 \mathrm{~cm}^{-3}$ to $2000 \mathrm{~cm}^{-3}$ ). The larger diurnal peaks at Site B are explained by the weak mixing due to the narrow cross-section of the valley. The peaks dissipate during daytime at Site B approaching a local minimum around 14:00-15:00 LT. At Site A, the daytime total number concentration for $D p<30 \mathrm{~nm}$ exhibits a strong short-term variability, which was found to be associated with the variable wind during the daytime. This high variability in daytime distribution is absent at Site B due to topographic controls in creating strong ridge-valley circulations and therefore a consistent diurnal wind profile, suggesting that the local sources do not affect Site B much in the afternoon, while they do in Site A. During peak times, the geometric mean diameter of the aerosol size distribution also decreases (Fig. 7g-h) more visibly at Site B (100 nm to $70 \mathrm{~nm}$ ). High variability in geometric mean diameter at Site A during daytime corresponds to high variability in the total particle number concentration of Aitken mode particles as discussed above. Otherwise, the geometric mean diameter at both sites is consistent during the night time (from midnight to early morning) and reaches similar values during 
Table 1. Parameters of the Multi-lognormal Fits for the measured aerosol size distribution.

\begin{tabular}{|c|c|c|c|c|c|c|c|c|c|}
\hline \multirow[t]{2}{*}{ Mode } & $\mathrm{N}\left(\mathrm{cm}^{-3}\right)$ & GM (nm) & G. Std (nm) & $\mathrm{N}\left(\mathrm{cm}^{-3}\right)$ & $\mathrm{GM}(\mathrm{nm})$ & G. Std (nm) & $\mathrm{N}(\mathrm{cm}-3)$ & $\mathrm{GM}(\mathrm{nm})$ & G. Std (nm) \\
\hline & \multicolumn{3}{|c|}{$\begin{array}{l}\text { Night time average } \\
\text { (11:00 p.m.-04:00 a.m.) }\end{array}$} & \multicolumn{3}{|c|}{$\begin{array}{c}\text { Day time average } \\
\text { (10:00 a.m.-05:00 p.m.) }\end{array}$} & \multicolumn{3}{|c|}{$\begin{array}{c}\text { Transition period average } \\
\text { (05:00 a.m.-10:00 a.m. \& } \\
\text { 05:00 p.m.-11:00 p.m.) }\end{array}$} \\
\hline \multicolumn{10}{|l|}{ SITE A } \\
\hline Unimodal & $147 \pm 47$ & $101 \pm 7$ & $0.65 \pm 0.03$ & $88 \pm 45$ & $93 \pm 11$ & $0.67 \pm 0.03$ & $265 \pm 120$ & $85 \pm 9$ & $0.67 \pm 0.03$ \\
\hline Bimodal & $152 \pm 41$ & $106 \pm 8$ & $0.59 \pm 0.05$ & $123 \pm 54$ & $105 \pm 17$ & $0.64 \pm 0.07$ & $237 \pm 117$ & $91 \pm 12$ & $0.65 \pm 0.05$ \\
\hline \multirow{4}{*}{ Trimodal } & $20 \pm 13$ & $27 \pm 16$ & $0.54 \pm 0.13$ & $76 \pm 116$ & $28 \pm 15$ & $0.55 \pm 0.15$ & $47 \pm 118$ & $22 \pm 11$ & $0.52 \pm 0.13$ \\
\hline & & & & $105 \pm 60$ & $117 \pm 60$ & $0.61 \pm 0.08$ & $162 \pm 88$ & $110 \pm 18$ & $0.61 \pm 0.08$ \\
\hline & & & & $148 \pm 124$ & $48 \pm 26$ & $0.47 \pm 0.15$ & $162 \pm 94$ & $53 \pm 18$ & $0.49 \pm 0.13$ \\
\hline & & & & $96 \pm 112$ & $17 \pm 9$ & $0.41 \pm 0.21$ & $46 \pm 60$ & $21 \pm 10$ & $0.33 \pm 0.15$ \\
\hline \multicolumn{10}{|l|}{ SITE B } \\
\hline Unimodal & $87 \pm 34$ & $106 \pm 13$ & $0.6 \pm 0.04$ & $143 \pm 48$ & $89 \pm 17$ & $0.66 \pm 0.03$ & $238 \pm 171$ & $84 \pm 14$ & $0.65 \pm 0.04$ \\
\hline \multirow[t]{2}{*}{ Bimodal } & $122 \pm 35$ & $103 \pm 13$ & $0.55 \pm 0.04$ & $133 \pm 54$ & $97 \pm 17$ & $0.6 \pm 0.06$ & $386 \pm 242$ & $80 \pm 12$ & $0.62 \pm 0.05$ \\
\hline & $18 \pm 11$ & $20 \pm 23$ & $0.61 \pm 0.14$ & $30 \pm 32$ & $23 \pm 15$ & $0.5 \pm 0.14$ & $51 \pm 114$ & $19 \pm 10$ & $0.47 \pm 0.14$ \\
\hline \multirow[t]{3}{*}{ Trimodal } & & & & $94 \pm 55$ & $123 \pm 25$ & $0.56 \pm 0.07$ & $305 \pm 177$ & $95 \pm 15$ & $0.62 \pm 0.1$ \\
\hline & & & & $94 \pm 102$ & $63 \pm 24$ & $0.48 \pm 0.15$ & $310 \pm 189$ & $55 \pm 15$ & $0.48 \pm 0.13$ \\
\hline & & & & $47 \pm 90$ & $19 \pm 10$ & $0.43 \pm 0.21$ & $67 \pm 132$ & $21 \pm 8$ & $0.31 \pm 0.13$ \\
\hline
\end{tabular}

the mid-afternoon, when the number concentration is at its minimum.

Based upon the observed strong diurnal cycle of aerosol size distribution, the parameters of the fitted distributions were classified into night time average (11:00 p.m. to 04:00 a.m.), daytime average (10:00 a.m. to 05:00 p.m.), and transition period average (05:00 a.m. to 10:00 a.m. and 05 p.m. to 11:00 p.m.). A summary of the distribution parameters is presented in Table 1 . As discussed above, both sites exhibit a consistent mode at $100 \mathrm{~nm}$ when either unimodal or bimodal distributions are dominant during the nonpeak periods suggesting that it corresponds to the regional background mode. The other smaller accumulation mode is superimposed upon it, whenever present.

\subsection{Aerosol composition}

At both sites, $\mathrm{PM}_{2.5}$ chemical composition is dominated by organic carbon, and the ionic composition was dominated by $\mathrm{SO}_{4}^{2-}$ and $\mathrm{NH}_{4}^{+}$(Fig. 8). Similar observations were reported by Carrico et al. (2003) for Nagarkot $\left(27.72^{\circ} \mathrm{N}, 85.52^{\circ} \mathrm{E}\right.$, $2150 \mathrm{~m}$ ), a hilltop location northwest of Site A. The statistics of mean concentration ( \pm one standard deviation) of the ionic species, organic carbon, water soluble organic carbon and elemental carbon are summarized in Table 2. Note that, since the sampling period and sampling hours were different, caution should be exercised in comparing the average concentrations for the two sites. For example, the average concentration at Site B is biased high due to very high concentrations on 3 June (Fig. 9) during a haze episode in the
Table 2. Ionic and Organic concentrations of aerosols sampled in Site A (4 to 25 May 2009) and Site B (28 May to 6 June) during the late pre-monsoon season 2009. All units are in $\mu \mathrm{g} / \mathrm{m}^{3}$.

\begin{tabular}{lll}
\hline \multicolumn{2}{l}{ Dhulikhel Besisahar } \\
\hline $\mathrm{Na}^{+}$ & $0.02 \pm 0.027$ & $0.014 \pm 0.024$ \\
$\mathrm{NH}_{4}^{+}$ & $1.12 \pm 0.47$ & $0.87 \pm 0.58$ \\
$\mathrm{~K}^{+}$ & $0.37 \pm 0.28$ & $0.36 \pm 0.28$ \\
$\mathrm{Ca}^{2+}$ & $0.0021 \pm 0.0012$ & $0.0012 \pm 0.001$ \\
$\mathrm{Cl}^{-}$ & $0.30 \pm 0.85$ & $0.00 \pm 0.00$ \\
$\mathrm{SO}_{4}^{2-}$ & $2.68 \pm 1.28$ & $2.21 \pm 1.32$ \\
$\mathrm{C}_{2} \mathrm{O}_{4}^{2-}$ & $0.31 \pm 0.15$ & $0.22 \pm 0.12$ \\
$\mathrm{WSON}^{2}$ & $0.43 \pm 0.24$ & $0.27 \pm 0.19$ \\
$\mathrm{WSOC}$ & $2.96 \pm 1.33$ & $2.62 \pm 0.93$ \\
$\mathrm{OC}$ & $11.09 \pm 2.49$ & $10.18 \pm 2.76$ \\
$\mathrm{EC}$ & $1.69 \pm 0.62$ & $1.10 \pm 0.39$ \\
\hline
\end{tabular}

IGP observed from the MODIS Terra $250 \mathrm{~m}$ resolution images as well as ground based observations (see further discussion in Sect. 3.4). The measured concentration of dominant ionic species $\left(\mathrm{NH}_{4}^{+}\right.$and $\left.\mathrm{SO}_{4}^{2-}\right)$ before and after the pollution episodes at Site B are within 5\% of the mean values reported by Carrico et al. (2003) for peak season (February-May) during $1999-2000$ at Langtang $\left(28.13^{\circ} \mathrm{N}, 85.6^{\circ} \mathrm{E}, 3920 \mathrm{~m}\right.$, see Fig. 1), a high altitude pristine location. Note that the data reported in the study is a short period data compared to the monthly averaged data for 2 years reported by Carrico et 

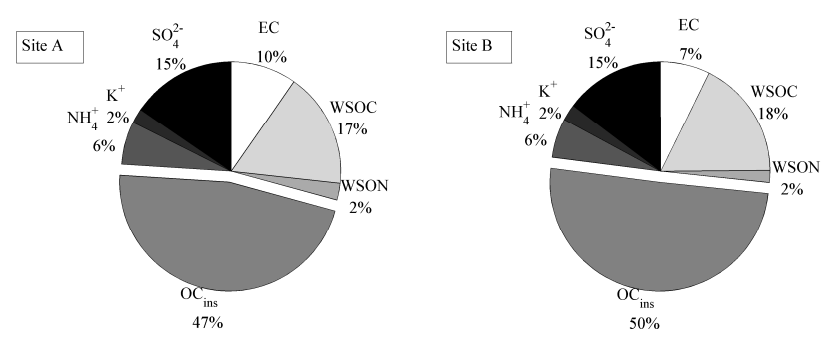

Fig. 8. Comparison of measured elemental carbon, organic carbon (insoluble), water soluble organic carbon /nitrogen and ionic composition of $\mathrm{PM}_{2.5}$ at Site A(left) and Site B (right) during the pre-monsoon season.

al. (2003). During the pollution episode at Site B, the ionic species concentration increases fourfold, dominated by increases in $\mathrm{SO}_{4}^{2-}$ and $\mathrm{NH}_{4}^{+}$concentrations (Fig. 10b). A similar rise in concentration of aerosol species was also observed at Site A, which coincided with synoptic scale haze episodes observed over the IGP (MODIS Rapid Response Image Subsets over Nepal). Synoptic scale haze was observed 4, 6, 10, 15, 17 and 22 May during the sampling period at Site A (Fig. 10a), based on $250 \mathrm{~m}$ resolution images from Terra (approximately around 10:00 LT). The measured daytime concentration of dominant ionic species $\left(\mathrm{NH}_{4}^{+}\right.$and $\left.\mathrm{SO}_{4}^{2-}\right)$ at Site $\mathrm{A}$ is less than $30 \%$ of the mean values reported by Carrico et al. (2003) in a nearby location (Nagarkot, Fig. 1). Likewise, the average daytime OC (Organic carbon) concentration measured at Site A $\left(11 \mu \mathrm{g} / \mathrm{m}^{3}\right)$ is significantly higher than the monthly average concentrations $\left(3.27 \mu \mathrm{g} / \mathrm{m}^{3}\right)$ reported by Stone et al. (2009) at Godavari $\left(27.59^{\circ} \mathrm{N}, 85.31^{\circ} \mathrm{E}\right.$, $1600 \mathrm{~m}$, south of Kathmandu Valley) during May of 2006, but less than $30 \%$ of the mean value (February-May 1999) reported by Carrico et al. (2003) at Nagarkot. These observations show there is large spatial variability in the relative chemical composition of aerosol, though the chemical composition per se is stable across the region.

The light absorbing properties of EC (Elemental Carbon) play a crucial role in atmospheric heating and surface cooling and hence are relevant to the radiative properties of aerosols (Ramanathan et al., 2007). The average EC concentrations at Sites A and B are $1.69 \pm 0.62 \mu \mathrm{g} / \mathrm{m}^{3}$ and $1.1 \pm 0.39 \mu \mathrm{g} / \mathrm{m}^{3}$ respectively. The mean $\mathrm{EC} / \mathrm{OC}$ ratios for Site $\mathrm{A}$ and $\mathrm{B}$ were $0.15 \pm 0.05$ and $0.11 \pm 0.01$, respectively (Fig. 11). These ratios are much smaller than previously reported values of $0.5 \pm 0.3$ by Venkataraman et al. (2002) for Bombay, India during February-March 1999. More recently, chemical properties of aerosols over the Himalayas were also reported by Ram et al. (2010) for field measurements carried out at Manora Peak, 2000 m a.m.s.l. (Fig. 1) from February 2005 to July 2008. Their reported mean monthly concentrations of $0.8 \pm 0.5 \mu \mathrm{gC} / \mathrm{m}^{3}$ for EC and $4.7 \pm 2.0 \mu \mathrm{gC} / \mathrm{m}^{3}$ for OC during May are much lower than the measured values for EC and OC during this field campaign (Table 2). a)

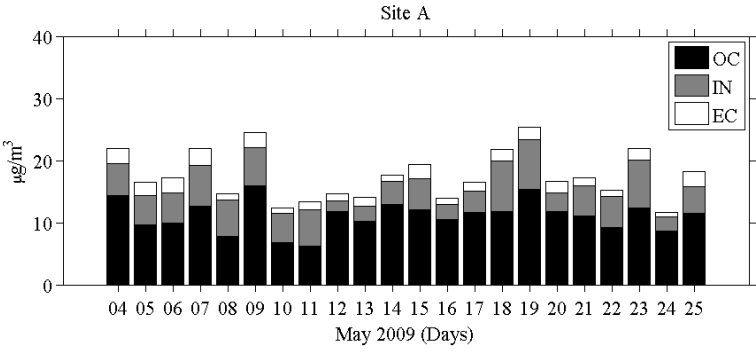

b)

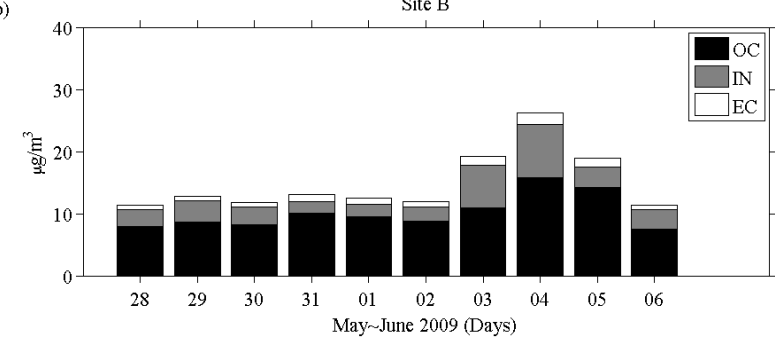

Fig. 9. Daily composition of $\mathrm{PM}_{2.5}$ in terms of organic carbon (OC), ionic compounds (IN) and elemental carbon (EC) for Site A (a) and Site B (b). The sudden peak in concentration at Site B is linked to a large scale pollution episode.

Note that the sampling durations of the two studies were different ( $\sim 2$ weeks in our case; $\sim 4$ months in 4 different years for Ram et al., 2010). The mean fractions of WSOC/OC for Site A and B were very similar at $0.27 \pm 0.12$ and $0.26 \pm 0.05$, respectively (Table 2). These values are much lower than the average WSOC/OC ratio of $0.51 \pm 0.12$ at Manora Peak for the month of May. However, the concentration of WSOC reported by Ram et al. for the month of May is $2.7 \pm 1.3 \mu \mathrm{gC} / \mathrm{m}^{3}$, which is similar to the WSOC concentration in Site A and B (Table 2). The OC concentration at Manora Peak is only $4.7 \pm 2 \mu \mathrm{gC} / \mathrm{m}^{3}$, thus much lower than in this study (Table 2) which explains the different WSOC/OC fractions. Jaffrezo et al. (2005) summarized the average data for WSOC/OC fractions from previous work that ranged from a low of 0.12 upto a maximum of 0.8 . The reported values of WSOC/OC fraction were $0.28-0.32$ (winter 1992) and 0.32-0.55 (summer 1992) for Tokyo (urban), $0.32 \pm 0.15$ for ACE-Asia, and 0.17-0.44 for Nanjing, China. The WSOC/OC fractions reported in this study are in line with those values.

Jaffrezo et al. (2005) also discuss the dependence of WSOC on temperature for measurements in the Alps. In the current study, similar dependence was exhibited by WSOC mass concentration and WSOC/OC fraction as a function of the diurnal amplitude of the air temperature, which probably explains much of the variance in the time series of WSOC for Site A (Fig. 11). However, it is difficult to infer any such temperature influence in WSOC/OC fraction at Site B. Previous studies by Facchini et al. (1999), Mayol-Bracero et al., (2002), Ervens et al. (2005), Mircea et al. (2005), and Decesari et al., (2005) have showed that large fractions of WSOC 
a)

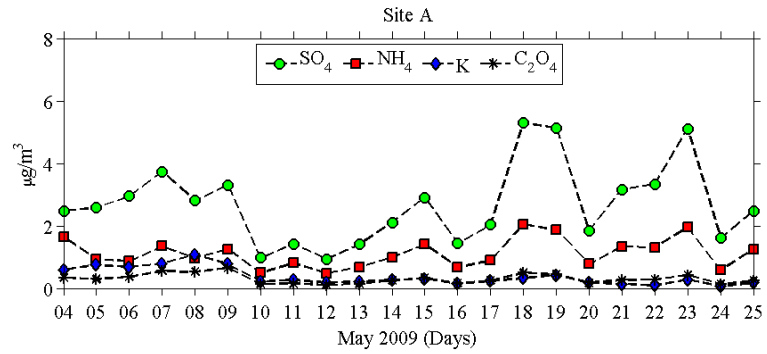

b)

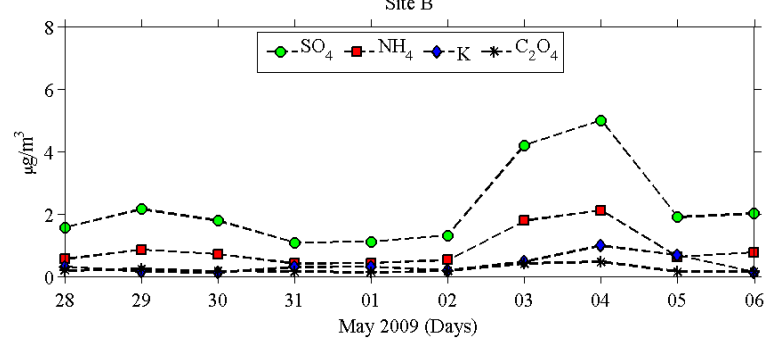

Fig. 10. Daily composition of major $\mathrm{PM}_{2.5}$ ionic compounds for Site A (a) and Site B (b). The ionic species were dominated by $\mathrm{NH}_{4}^{+}$and $\mathrm{SO}_{4}^{2-}$ at both sites with lower mean concentrations at Site $\mathrm{B}$. The peak in the ionic concentrations is associated with the presence of synoptic scale pollution episodes.

can potentially influence the aerosol hygroscopic growth and activation. The dominance of particulate organic matter in the $\mathrm{PM}_{2.5}$ filter samples, and significant WSOC/OC ratios at both sites in this study suggest possible influence of WSOC in the $\mathrm{CCN}$ activation for this region, which needs to be further examined.

Total nitrogen concentration (TN) was also measured during the filter analysis. The water soluble organic nitrogen (WSON) was estimated from TN by subtracting the inorganic nitrogen concentration. The WSON concentrations were $1.30 \pm 0.51 \mu \mathrm{g} / \mathrm{m}^{3}$ and $1.10 \pm 0.39 \mu \mathrm{g} / \mathrm{m}^{3}$ for Site A and Site B, respectively (Fig. 12). The WSON/TN fraction was $0.32 \pm 0.10$ for Site A, and $0.28 \pm 0.05$ for Site B. Data on this aerosol component are very scarce in the literature. It is interesting to note that the few studies report similar WSON/TN ratios around the world: WSON was shown to account for 30\% of total particulate nitrogen mass in Beijing, China (Duan et al., 2009); 19-25\% of total aerosol nitrogen in Cape Grim, Australia (Mace et al., 2003); and approximately $33 \%$ of the total nitrogen in Chapel Hill, NC, USA (Lin et al., 2010).

For Site B, there was only one strong precipitation event in the morning of 5 June during the sampling period (Fig. 2d). Rainfall washed out the low level aerosol, which is reflected by the decrease in the concentrations of all the analyzed species at the same time. Overall, the differences in the observed daily variability in the aerosol concentrations at Site A compared to Site B are explained by the wash out due to such periodic precipitation events (Fig. 2c). During the subsequent dry periods, the aerosol concentration tends to in- a)

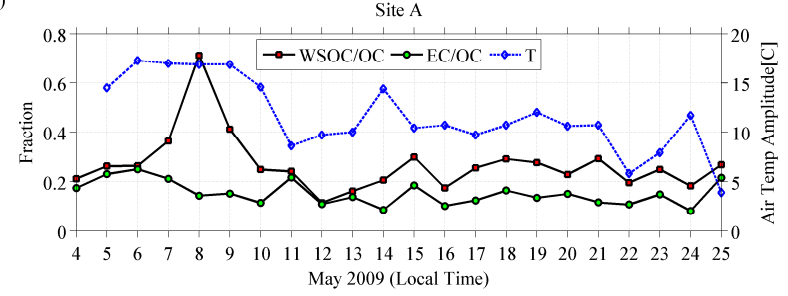

b)

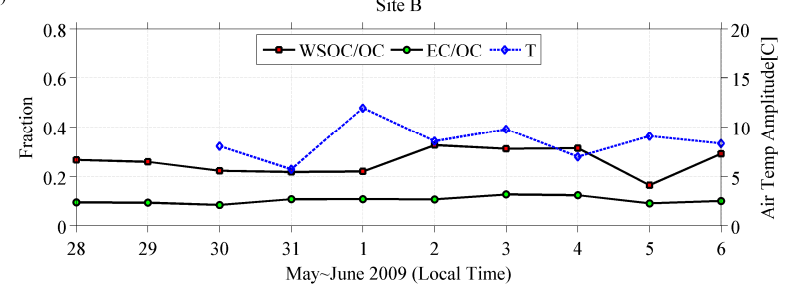

Fig. 11. Daily ratio of water soluble organic carbon (WSOC/OC) and elemental carbon to organic carbon $(\mathrm{EC} / \mathrm{OC})$ and the diurnal temperature amplitude (maximum daily temperature-minimum daily temperature) for Site A (a) and Site B (b). The EC/OC ratio was lower in Site B compared to Site A.

a)
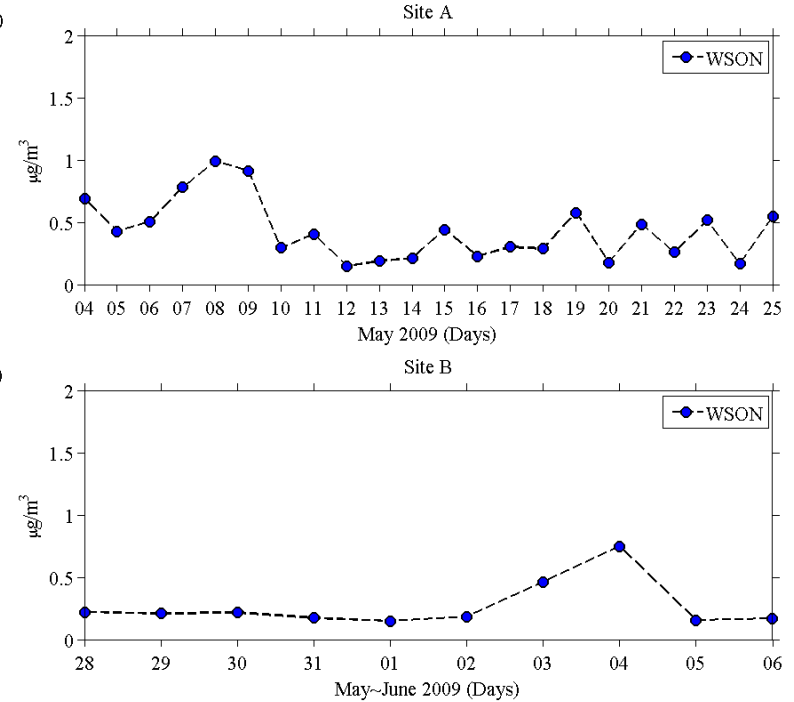

Fig. 12. Daily composition of water soluble organic nitrogen (WSON) Site A (a) and Site B (b). Similar peak in WSON concentration is also observed for Site B associated with pollution episode.

crease in the days after rainfall (for example, 5-7 May, 13-15 May, 17-19 May and 22-23 May, Fig. 9a), indicating accumulation in the valley. These periods also coincide with the presence of synoptic scale haze as discussed above. Aryal et al. (2009) discuss these accumulation effects for $\mathrm{PM}_{2.5}$ measured in the Kathmandu Valley during the winter months caused by stagnant wind and temperature inversions. The observations from Site A in this study indicate that such accumulation effects are also present for Site A during the premonsoon season. 
a)

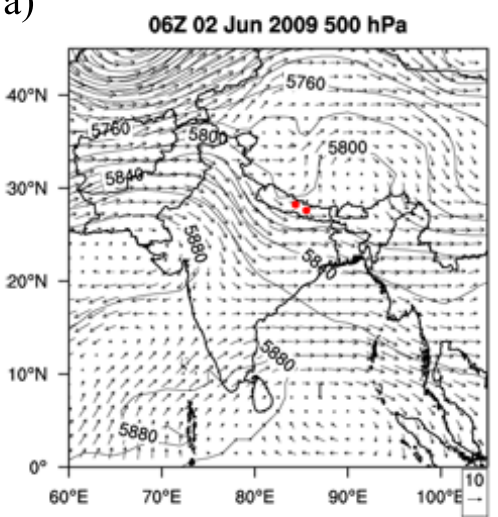

b) 06202 Jun $2009900 \mathrm{hPa}$

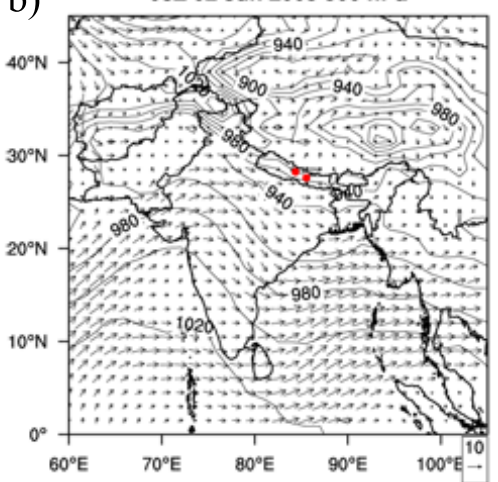

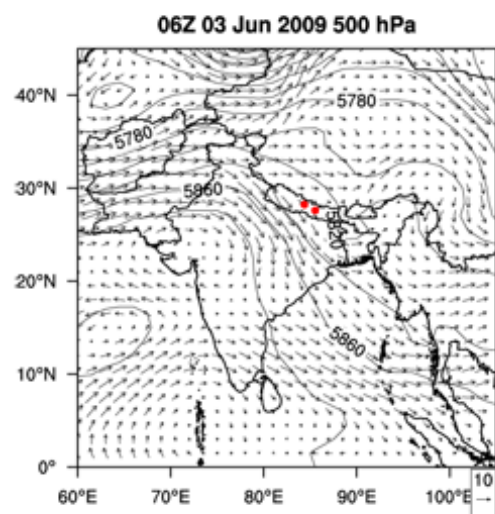

$06 \mathrm{Z} 03$ Jun $2009900 \mathrm{hPa}$

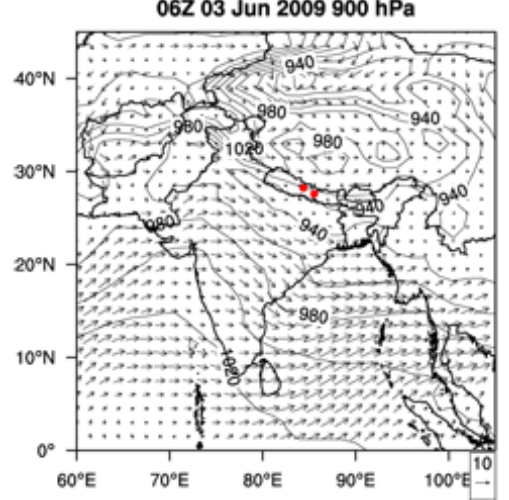

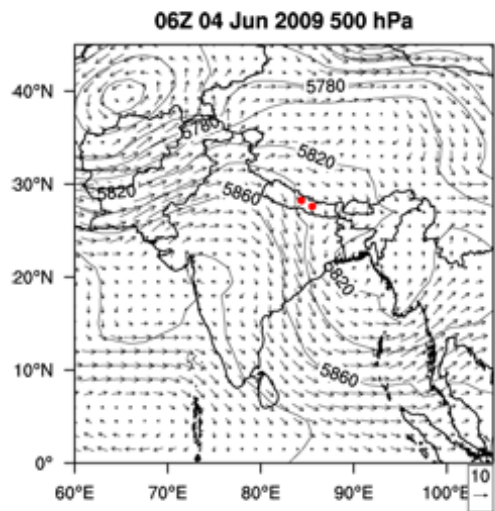

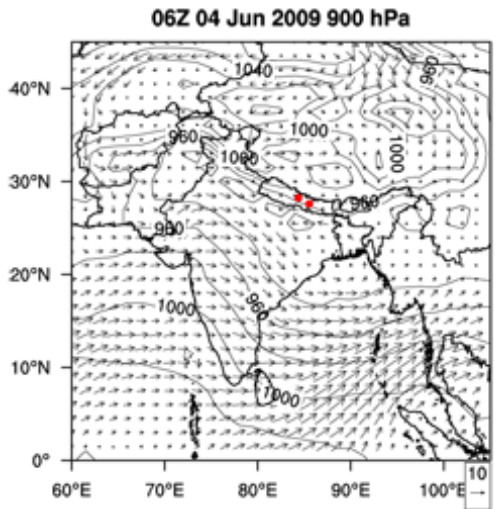

Fig. 13. Regional scale wind flow pattern during the sampling period at Site B (Besisahar) at (a) $500 \mathrm{hPa}$ and (b) $900 \mathrm{hPa}$. The circular red dots represent the two sampling sites. Note the relatively stagnant flow as the synoptic wind ( $900 \mathrm{hPa})$ approaches the southern outermost foothills of Himalayas along the Nepal India border. Geopotential heights (m) and horizontal winds (m/s) were obtained from ERA Interim dataset. The contour lines for geopotential height are plotted at interval of $20 \mathrm{~m}$.
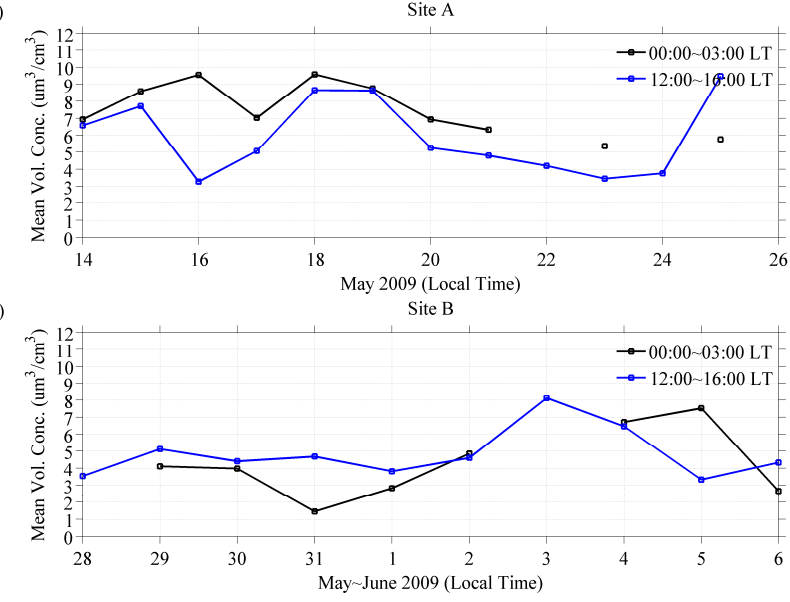

Fig. 14. Time series of mean volume concentration measured at night (23:00 to 03:00 LT) and afternoon (12:00 to 16:00 LT) from the SMPS. The missing values are the periods when no SMPS data were available due to electricity outages during the night.

\subsection{Regional influence on aerosol spectra}

On 3 June, 2009, visible haze was observed in the south and south-east direction from the sampling site indicating transport of pollutants from the IGP (as observed from MODIS Terra $250 \mathrm{~m}$ resolution images, not shown here). The steady increase in the concentration of all the analyzed species over that period also suggests the presence of non-local pollutants. A precipitation event on 5 June washed away this effect. Figure $2 \mathrm{~b}$ shows the typical diurnal wind profile at Site B. UpValley wind strengthens from 09:00 to 14:00 LT and then begins to weaken afterwards in afternoon as mountain downslope winds begin to establish (north-westerly flow). The vertical profiles of wind from radiosonde data at lower levels (850-900 mb) in Besisahar during June 1999 reported by Barros and Lang (2003) also show the presence of northwesterly mountain wind from mid-night to morning, which transitions to up-valley wind around 09:00 LT in the morning and strengthens during daytime. These observations are consistent with the descriptive models provided by Defant (1949, 1951), Vergeiner and Dreiseitl (1987), Rampanelli et al. (2004), Mcnider et al. (1984) for mountain valley 
circulations in narrow valleys. Therefore, mountain valley wind mechanisms can be expected to play an important role in transporting the pollutants further inwards into the inner Himalayan region from the low lying plains.

At the synoptic scale, $500 \mathrm{hPa}$ geopotential height data from ERA Interim (ECMWF's latest global atmospheric reanalysis product) show that the development of low pressure systems above Afghanistan cause westerly flow above Nepal which veers north-westerly (Fig. 13). Shrestha et al. (2000) noted a rise in aerosol concentration at Phortse, $4000 \mathrm{~m}$ a.m.s.l., when the $500 \mathrm{hPa}$ flow became southwesterly. The $900 \mathrm{hPa}$ geopotential height from ERA Interim shows well developed south-westerly flow from the Arabian Sea, through the Thar Desert, then flowing parallel to the Himalayan range. The flow appears to be stagnant around the India-Nepal border on the IGP as it meets opposing flow from the Bay of Bengal. Coinciding with the synoptic scale flows, the MODIS satellite images captured a well developed haze event along the IGP adjoining Nepal and in the inner river valleys pockets of Nepal on 3-5 June. During this period, the SMPS data show a shift in the minimum total volume concentration to a higher value (Fig. 4c) accompanied by an increase in the geometric mean diameter (Fig. 4d). The ERA Interim data at its coarse resolution cannot resolve the detailed wind fields in the inner regions of complex terrain proper but observed surface wind profiles suggest the transport of pollutants along the river valleys of Nepal from the southern lower plains via mountain-valley wind mechanisms (Zängl et al., 2000; Barros and Lang, 2003). On the other hand, the precipitation event in the morning of 5 June (Fig. 2d) washed away the haze build-up in the previous 3 days, which is also reflected in the SMPS data (drop in max geometric mean diameter along with the minimum total volume concentration).

The above analysis was further extended for Site A as well, using the observed mean volume concentration during the afternoon (12:00 to 16:00 LT) and night time (23:00 to 03:00 LT). The interval range was selected such that minimum volume concentration was observed during that period of the day (Fig. 14). As discussed earlier the synoptic scale haze was observed during 15, 17 and 22 May based on MODIS rapid response images from Terra. From 23 May onwards, due to increased cloud cover, it is impossible to ascertain whether there was any haze event. Significant rainfall events were observed on 15, 16, 20, 21 and 25 May. In general, Fig. 14a shows that the mean volume concentration during the afternoon, as well as at night, increases in the presence of haze events relative to previous day (e.g. 15 and 17 May), while the concentration decreases after the rainfall event $(16,20$ and 21 May). A corresponding increase (and decrease) in elemental carbon and inorganic aerosol composition due to haze (and rainfall) was also observed relative to previous day (Fig. 10a).
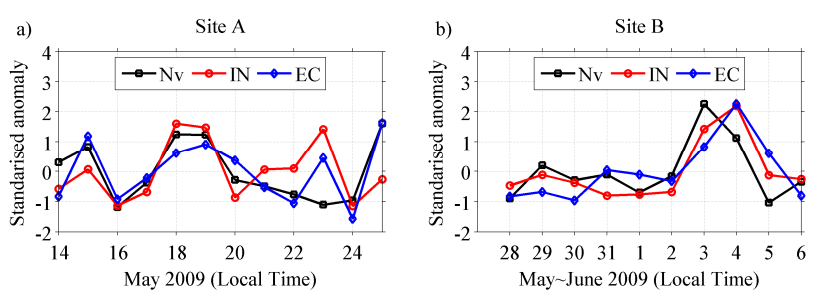

Fig. 15. Time series of standardized anomalies of afternoon mean volume concentration (Nv), inorganic species (IN) and elemental carbon (EC). The mean volume concentration at night was not used due to some missing values.

Further, the standardized anomalies of inorganic species (IN), elemental carbon (EC), afternoon mean volume concentration $(\mathrm{Nv})$ were estimated to investigate the linkages between aerosol volume concentration and the aerosol mass concentration of different species, during regional scale haze events. Figure 15 shows a strong in-phase relationship between observed mean afternoon volume concentration and aerosol species concentrations at both sites. Specifically, a clear peak is observed during the synoptic haze events followed by dry periods (Site A: 15, 17-19, 23 and 25 May, and Site B: 3 to 4 June). An unambiguous reduction in aerosol mass concentration and volume concentration is observed after a strong rainfall event at both sites as well. The above analysis was also repeated for the transition periods when aerosol peak was observed (03:00-10:00 LT and 16:00-23:00 LT), which showed consistent results as in the daytime and nighttime periods. Thus, in the presence of regional-scale haze and dry periods, the mean volume aerosol concentrations increases and so does the aerosol mass concentration. Therefore, over a specific time window, significant day-to-day variability in the aerosol size distribution along with the increase in concentrations of analyzed species can be attributed to the influence of broader regional scale aerosol transport.

\section{Summary and conclusions}

The combination of aerosol size distribution and chemical composition sampled in Dhulikhel (Site A) and Besisahar (Site B) provides the first picture of the aerosol distribution in the foothills of the central Himalaya. Both sites exhibit a strong diurnal cycle with aerosol peaks both for $D p<$ $30 \mathrm{~nm}$ and $D p>30 \mathrm{~nm}$ during the morning and evening hours. The aerosol peaks are associated with the transient stage of boundary layer growth and decay processes, when the wind is weak. Further, this period also coincides with the peak in local household activities (mainly combustion of fuels while cooking). The diurnal cycle of the measured aerosol number concentration shows strong linkages to the topography of the sampling site due to the modulating 
effects of mountain-valley winds and ridge-valley circulations. This was also noted earlier by Panday and Prinn (2009) and Panday et al. (2009) in their study to explain diurnal $\mathrm{CO}$ peaks in Kathmandu Valley. The total number concentration/geometric mean diameter at both sites approached a minimum/maximum during the afternoon coinciding with the nighttime number concentration/geometric mean size. The classification of the lognormal fittings of the aerosol distributions indicated the predominance of unimodal distribution at night, whereas the bimodal distribution was mostly dominant during the daytime. The fitted distributions indicated a consistent larger mode around $100 \mathrm{~nm}$ which is usually the oldest, most processed background aerosol. The smaller mode was centered at $20 \mathrm{~nm}$, which suggests the presence of fresh aerosol, though not necessarily local.

The chemical composition of $\mathrm{PM}_{2.5}$ is dominated by organic matter at both sites. Organic carbon comprises the major fraction (64-68\%) of the aerosol concentration followed by ionic species (24-26\% mainly $\mathrm{SO}_{4}^{2-}$ and $\mathrm{NH}_{4}^{+}$). Elemental carbon compromised 7-10\% of the total composition. A large fraction of $\mathrm{OC}$ was also found to be water soluble (nearly $27 \%$ at both sites). The variability in the aerosol concentration at Site A was found to be strongly correlated with the periodic precipitation events and the presence of synoptic scale haze. A strong decrease in aerosol concentration after rainy days is consistent with the scavenging role of precipitation. In the presence of regional scale haze and dry periods, the mean volume aerosol concentrations and aerosol mass were found to increase. A relatively stronger correlation between day time volume concentration and elemental carbon for Site A $(r=0.76)$, daytime volume concentration and inorganics for Site B $(r=0.79)$, nighttime volume concentration and organic carbon for Site B $(0.75)$ was observed. During other periods, although the correlation is present, its magnitude is relatively weak $(r<=0.70$ i.e. $r^{2}<0.5$ ). Longer term measurements are necessary to achieve more robust statistics and to better understand the influence of large scale transport of aerosol in this region.

During the sampling period at Site B, a single large scale pollution episode was observed which resulted in the increase of all analyzed aerosol species. The synoptic scale wind during that period, along with the observed diurnal profile of surface wind, suggests that daytime upvalley wind might be responsible for transporting aerosols from the low lying plains to the inner valleys of the central Himalayas. Results from this study provide new insights and confirm previous work regarding the role of mountain-valley circulations in the diurnal cycle of aerosol number and mass concentration across the Middle Himalayan range, and document evidence of the role of synoptic scale transport and weather controls (haze events and rainfall) in modulating the amplitude of the diurnal cycle and day-to-day variability of aerosols in the pre-monsoon season.
Acknowledgements. The research was funded in part by NASA Earth System Science Fellowship with the first author and by NASA grant NNX09AH39G CR\# 298697 NS000125. We are grateful to W. K. M. Lau and S. C. Tsay for allowing us the opportunity to participate in the JAMEX09 field campaign. Panna Thapa, the Dean of Science at Kathmandu University, Sanjay Sharma, and Rijan Bhakta Kayastha provided much appreciated help with logistics and planning. Rawad Saleh's expertise was instrumental to operating the SMPS systems under difficult conditions, and we also thank N. C. Hsu, Ritesh Gautam, Q. Ji, C. Li, and S. Bell for their cooperation and support before and throughout the field campaign. The author is also thankful to Samir Shrestha from Kathmandu University who assisted with sampling at Dhulikhel. We extend special thanks to Deepak Aryal and Amrit Ghale for their valuable assistance during sampling at Besisahar. Finally, the first author is especially indebted to M. Lin for helping with the IC/TOC analysis, and to Michael Hays for the OC/EC analysis.

Edited by: G. McFiggans

\section{References}

Andreae, M. O., Rosenfeld, D., Artaxo, P., Costa, A. A., Frank, G. P., Longo, K. M., and Silvas-Dias M. A., F.: Smoking rain clouds over the Amazon, Science, 303, 1337-1342, 2004.

Aryal, R. K., Lee, B.-K., Karki, R., Gurung, A., Baral, B., and Byeon, S.-H.: Dynamics of $\mathrm{PM}_{2.5}$ concentrations in Kathmandu Valley, Nepal, J. Hazardous Materials, 168, 732-738, 2009.

Barros, A. P. and Lang, T. J.: Monitoring the Monsoon in the Himalayas: Observations in Central Nepal, June 2001, Mon. Weather Rev., 131, 1408-1427, 2003.

Barros, A. P. and Lettenmaier, D. P.: Dynamic modeling of orographically-induced precipitation, Rev. Geophys., 32, 265284, 1994.

Barros, A. P., Kim, G., Williams, E., and Nesbitt, S. W.: Probing orographic controls in the Himalayas during the monsoon using satellite imagery, Nat. Hazards Earth Syst. Sci., 4, 29-51, doi:10.5194/nhess-4-29-2004, 2004.

Bonasoni, P., Laj, P., Angelini, F., Arduini, J., Bonafe, U., Calzolari, F., Cristofanelli, P., Decesari, S., Facchini, M. C., Fuzzi, S., Gobbi, G. P., Maione, M., Marinoni, A., Petzold, A., Roccato, F., Roger, J. C., Sellegri, K., Sprenger, M., Venzac, H., Verza, G. P., Villani, P., and Vuillermoz, E.: The ABC-Pyramid Atmospheric Research Observatory in Himalaya for aerosol, ozone and halocarbon measurements, Sci. Total Environ., 391, 252-261, 2008.

Carrico, C. M., Bergin, M. H., Shrestha, A. B., Dibb, J. E., Gomes, L., and Harris, J. M.: The importance of carbon and mineral dust to seasonal aerosol properties in the Nepal Himalaya, AE Intl.Asia, 37, 2811-2824, 2003.

Cohard, J.-M., Pinty, J.-P., and Bedos, C.: Extending Twomey's Analytical Estimate of Nucleated Cloud Droplet Concentration from CCN spectra, J. Atmos. Sci., 55, 3348-3357, 1998.

Cohard, J.-M., Pinty, J.-P., and Suhre, K.: On the parameterization of activation spectra from cloud condensation nuclei microphysical properties, J. Geophys. Res., 105, 11753-11766, 2000.

Decesari, S., Facchini, M. C., Fuzzi, S., McFiggans, G. B., Coe, H., and Bower, K. N.: The water-soluble organic component of sizeaggregated aerosol, cloud water and wet depositions from Jeju Island during ACE-Asia, Atmos. Environ., 39, 211-222, 2005. 
Defant, F.: Zur theorie der Hangwinde, nebst Bemerkungen zur Theorie der Berg- und Talwinde. Arch. Meteor. Geophys. Bioklim.,A1, 421-450, English translation: Whiteman, C. D., and E. Dreiseitl, 1984: A theory of slope winds, along with remarks on the theory of mountain winds and valley winds. Alpine Meteorology: Translations of Classic Contributions by A. Wagner, E. Ekhart and F. Defant. PNL-5141/ASCOT-84-3, Pacific Northwest Laboratory, 95-121, 1951: Local Winds, in: Compendium of Meteorology, edited by: Malone, T. F., AMS, Boston, 655672, 1949.

Duan, F. K., Liu, X. D., He, K. B., and Dong, S. P.: Measurements and characteristics of nitrogen-containing compounds in atmospheric particulate matter in Beijing, China, Bulletin of Environmental Contamination and Toxicology, 82, 332-337, 2009.

Ervens, B., Feingold, G., and Kreidenweis, S. M.: Influence of water-soluble organic carbon on cloud drop number concentration, J. Geophys. Res., 110, D18211, doi:10.1029/2004JD005634, 2005.

Facchini, M. C., Mircea, M., Fuzzi, S., and Charlson, R. J.: Cloud albedo enhancement by surface-active organic solutes in growing droplets, Nature, 401, 257-259, 1999.

Hindman, E. E. and Upadhyay, B. P.: Air pollution transport in the Himalayas of Nepal and Tibet during the 1995-1996 dry seasons, Atmos. Environ., 36, 727-739, 2002.

Ikegami, K., Inoue, J., Higuchi, K., and Ono, A.: Atmospheric aerosol particles observed in high altitude Himalayas, Journal of the Japanese Society of Snow and Ice, 40, 50-55, 1978.

Jaffrezo, J.-L., Aymoz, G., Delaval, C., and Cozic, J.: Seasonal variations of the water soluble organic carbon mass fraction of aerosol in two valleys of the French Alps, Atmos. Chem. Phys., 5, 2809-2821, doi:10.5194/acp-5-2809-2005, 2005.

Khain, A., Ovtchinnikov, M., Pinsky, M., Pokrovsky, A., and Krugliak, H.: Review: Notes on the state-of-art numerical modeling of cloud microphysics, Atmos. Res., 55, 159-224, 2000.

Khvorostyanov, V. I. and Curry, J. A.: Aerosol size spectra and CCN activity spectra: Reconciling the lognormal, algebraic, and power laws, J. Geophys. Res., 111, D12202, doi:10.1029/2005JD006532, 2006.

Komppula, M., Lihavainen, H., Hyvärinen, A.-P., Kerminen, V.-M., Panwar, T. S., Sharma, V. P., and Viisanen, Y.: Physical properties of aerosol particles at a Himalayan background site in India, J. Geophys. Res., 114, D12202, doi:10.1029/2008/JD011007, 2009.

Lang, T. J. and Barros, A. P.: An Investigation of the Onsets of 1999 and 2000 Monsoons in Central Nepal, Mon. Weather Rev., 130, 1299-1316, 2002.

Lascaux, F., Richard, E., and Pinty, J.-P.: Numerical Simulation of three different MAP IOPs and the associated microphysical processes, Q. J. Roy. Meteorol. Soc., 132, 1907-1926, 2006.

Lau, K.-M., Ramanathan, V., Wu, G.-X., Li, Z., Tsay, S. C., Hsu, C., Sikka, R., Holben, B., Liu, D., Tartari, G., Chin, M., Koudelova, P., Chen, H., Ma, Y., Huang, J., Taniguchi, K., and Zhang, R.: The Joint Monsoon Experiment-A new Challenge for Monsoon Climate Research, B. Am. Meteorol. Soc., 89, 369-383, doi:10.1175/BAMS-89-3-369, 2008.

Lin, M., Walker, J., Geron, C., and Khlystov, A.: Organic nitrogen in $\mathrm{PM}_{2.5}$ aerosol at a forest site in the Southeast US, Atmos. Chem. Phys., 10, 2145-2157, doi:10.5194/acp-10-21452010, 2010.
Mace, K. A., Artaxo, P., and Duce, R. A.: Water-soluble organic nitrogen in Amazon Basin aerosols during the dry (biomass burning) and wet seasons, J. Geophys. Res., 108, 4512, doi:10.1029/2003JD003557, 2003.

Mayol-Bracero, O. L., Guyon, P., Graham, B., Roberts, G., Andreae, M. O., Decesari, S., Facchini, M. C., Fuzi, S., and Artaxo, P.: Water-soluble organic compounds in biomass burning aerosols over Amazonia, 2. Apportionment of the chemical composition and importance of the polyacidic fraction, J. Geophys. Res., 107(D20), 8091, doi:10.1029/2001JD00052, 2002.

McNider, R. T. and Pielke, R. A.: Numerical Simulation of Slope and Mountain Flows, J. Climate Appl. Meteorol., 23, 14411453, 1984.

Mircea, M., Facchini, M. C., Decesari, S., Cavalli, F., Emblico, L., Fuzzi, S., Vestin, A., Rissler, J., Swietlicki, E., Frank, G., Andreae, M. O., Maenhaut, W., Rudich, Y., and Artaxo, P.: Importance of the organic aerosol fraction for modeling aerosol hygroscopic growth and activation: a case study in the Amazon Basin, Atmos. Chem. Phys., 5, 3111-3126, doi:10.5194/acp-53111-2005, 2005.

Panday, A. K. and Prinn, R. G.: Diurnal Cycle of air pollution in the Kathmandu Valley, Nepal: Observations, J. Geophys. Res., 114, D09305, doi:10.1029/2008JD009777, 2009.

Panday, A. K., Prinn, R. G., and Schär, C.: Diurnal cycle of air pollution in the Kathmandu Valley, Nepal: 2. Modeling results, J. Geophys. Res., 114, D21308, doi:10.1029/2008JD009808, 2009.

Ram, K., Sarin, M. M., and Hegde, P.: Long-term record of aerosol optical properties and chemical composition from a high-altitude site (Manora Peak) in Central Himalaya, Atmos. Chem. Phys. Discuss., 10, 7435-7467, doi:10.5194/acpd-107435-2010, 2010.

Ramanathan, V. and Ramana, M. V.: Persistent, Widespread, and Strongly Absorbing Haze Over the Himalayan Foothills and the Indo-Gangetic Plains, Pure Appl. Geophys., 162, 1609-1626, 2005.

Ramanathan, V., Crutzen, P.,J., Kiehl, J. T., and Rosenfeld, D.: Aerosols, Climate, and the Hydrological Cycle, Science, 294, 2119-2124, 2001.

Rampanelli, G., Zardi, D., and Rotunno, R.: Mechanisms of UpValley Winds, J. Atmos. Sci., 61, 3097-3111, 2004.

Razzak, H.-A., Ghan, S. J., and Carpio, C. R.: A parameterization of aerosol activation 1. Single aerosol type, J. Geophys. Res., 103, 6123-6131, 1998.

Regmi, R. P., Kitada, T., and Kurata, G.: Numerical Simulation of Late Wintertime Local Flows in Kathmandu Valley, Nepal: Implication for Air Pollution Transport, J. Appl. Meteor., 42, 389403, 2003.

Rissler, J., Vestin, A., Swietlicki, E., Fisch, G., Zhou, J., Artaxo, P., and Andreae, M. O.: Size distribution and hygroscopic properties of aerosol particles from dry-season biomass burning in Amazonia, Atmos. Chem. Phys., 6, 471-491, doi:10.5194/acp6-471-2006, 2006.

Rosenfeld, D. and Lensky, I. M.: Satellite-Based Insights into Precipitation Formation Processes in Continental and Maritime Convective Clouds, B. Am. Meteorol. Soc., 79, 2457-2476, 1998.

Rotunno, R. and Houze, R. A.: Lessons on orographic precipitation from the Mesoscale Alpine Programme, Q. J. Roy. Meterol. Soc., 133, 811-830, 2007.

Sellegri, K., Laj, P., Venzac, H., Boulon, J., Picard, D., Villani, P., 
Bonasoni, P., Marinoni, A., Cristofanelli, P., and Vuillermoz, E.: Seasonal variations of aerosol size distributions based on longterm measurements at the high altitude Himalayan site of Nepal Climate Observatory-Pyramid (5079 m), Nepal, Atmos. Chem. Phys., 10, 10679-10690, doi:10.5194/acp-10-10679-2010, 2010.

Shrestha, P. and Barros, A. P.: Joint spatial variability of aerosol, clouds and rainfall in the Himalayas from satellite data, Atmos. Chem. Phys., 10, 8305-8317, doi:10.5194/acp-10-8305-2010, 2010.

Shrestha, A. B., Wake, C. P., Dibb, J. E., Mayewski, P. A., Whitlow, S. I., Carmichael, G. R., and Ferm, M.: Seasonal variations in aerosol concentrations and compositions in the Nepal Himalaya, Atmos. Environ., 34, 3349-3363, 2000.

Shrestha, A. B., Wake, C. P., Dibb, J. E., and Whitlow, S. I.: Aerosol and Precipitation Chemistry at a Remote Himalayan Site in Nepal, Aerosol Sci. Technol., 36, 441-456, 2002.

Stone, E. A., Schauer, J. J., Pradhan, B. B., Dangol, P. D., Habib, G., Venkataraman, C., and Ramanathan, V.: Characterization of emissions from South Asian biofuels and application to source apportionment of carbonaceous aerosol in the Himalayas, J. Geophys. Res.-Atmos., 115, D06301, doi:10.1029/2009JD011881, 2009.

Tao, W.-K., Li, X., Khain, A., Matsui, T., Lang, S., and Simpson, J.: Role of atmospheric aerosol concentration on deep convective precipitation: Cloud-resolving model simulations, J. Geophys. Res., 112, D24S18, doi:10.1029/2007JD008728, 2007.
Turpin, B. J., Cary, R. A., and Huntzicker, J. J.: An in situ, time-resolved analyzer for aerosol organic and elemental carbon, Aerosol Sci. Tech., 12(1), 161-171, 1990.

Venkataraman, C., Reddy, C. K., Josson, S., and Reddy, M. S.: Aerosol size and chemical characteristics at Mumbai, India during the INDOEX-IFP (1999), Atmos. Environ., 36, 1979-1991, 2002.

Venzac, H., Sellegri, K., Laj, P., Villani, P., Bonasoni, P., Marinoni, A., Cristofanelli, P., Calzolari, F., Fuzzi, S., Decesari, S., Facchini, M.-C., Vuillermoz, E., and Verza, G. P.: High frequency new particle formation in the Himalayas, P. Natl. Acad. Sci., 105, 15666-15671, 2008.

Vergeiner, I. and Dreiseitl, E.: Valley Winds and Slope windsObservations and Elementary Thoughts, Meteorol. Atmos. Phys., 36, 264-286, 1987.

White, A. B., Neiman, P. J., Ralph, F. M., Kingsmill, D. E., and Persson, P. O. G.: Coastal Orographic Rainfall Processes Observed by Radar during the California Land-Falling Jets Experiment, J. Hydrometeorol., 4, 264-282, 2003.

Zängl, G., Egger, J., and Wirth, V.: Diurnal Winds in the Himalayan Kali Gandaki Valley. Part II: Modeling., Mon. Weather Rev., 129, 1062-1080, 2000. 